\title{
Risk Assessment of Spent Nuclear Fuel Facilities Considering Climate Change
}

\author{
Silvia Tolo *1, Edoardo Patelli ${ }^{1}$, and Michael Beer ${ }^{1,2,3}$ \\ ${ }^{1}$ Institute for Risk and Uncertainty, University of Liverpool, UK \\ ${ }^{2}$ Institute for Risk and Reliability, Leibniz University Hannover, DE \\ ${ }^{3}$ Shanghai Institute of Disaster Prevention and Relief, Tongji University, CN
}

Published in Journal of Risk Uncertainty in Engineering Systems

on April 2016

\begin{abstract}
Natural hazards have the capability to affect technological installations, triggering multiple failures and putting the population and the surrounding environment at risk. Global climate change introduces an additional and not negligible element of uncertainty to the vulnerability quantification, threatening to intensify (both in terms of frequency and severity) the occurrence of extreme climate events. Sea level extremes and extreme coastal high waters are expected to change in the future as a result of both changes in atmospheric storminess and mean sea level rise, as well as extreme precipitation events. These trends clearly suggest a parallel increase in the risks affecting technological installations and the subsequent need for mitigation measures to enhance the reliability of existing systems and to improve the design standards of new facilities. In spite of this situation, the scientific research in this field lacks robust and reliable tools for this kind of assessment, often relying on the adoption of oversimplified models or strong assumptions, which affect the credibility of the results. The main purpose of this study is to provide a novel and general model for the evaluation of the risk of exposure of spent nuclear fuel stored in a facility subject to flood hazard, investigating the potential and limitations of Bayesian networks (BNs) in this field. The network aims to model the interaction

*s.tolo@liverpool.ac.uk
\end{abstract}


between extreme weather conditions and the technological installation, as well as the propagation of failures within the system itself, taking into account the dependencies among the different components and the occurrence of human error. A real-world application concerning the nuclear power station of Sizewell B in East Anglia, in the United Kingdom, is extensively described, together with the models and data set used. Results are presented for three different time scenarios in which climate change projections have been adopted to estimate future risks.

\section{Introduction}

The occurrence of technological disasters triggered by natural hazards (generally referred to as Natech events) has progressively raised concerns in the scientific community and increased the awareness of public opinion about the vulnerability of technological installations and infrastructures to extreme weather conditions. In addition, global climate change introduces an additional and not negligible element of uncertainty to the overall risk, threatening to intensify (both in terms of frequency and severity) the occurrence of extreme climate events. Evidence of a substantial increase in heavy precipitation events has been described in Trenberth et al. [68]. The same study stated that "it is likely that there have been increases in the number of heavy precipitation events (e.g., 95th percentile) within many land regions, even in those where there has been a reduction in total precipitation amount, consistent with a warming climate, and observed significant increasing amounts of water vapour in the atmosphere. Increases have also been reported for rarer precipitation events ( 1 in 50-year return period). "This globally observed change in daily winter precipitation in the period 1901-2000 has been confirmed by more detailed country-based studies, such as Maraun et al. [44] in the United Kingdom, and appears to be consistent with the expected response to anthropogenic forcing [61]. Coherent with the observed increasing trends over the twentieth century, projected changes show that the frequency of heavy precipitation or proportion of total precipitation from heavy precipitation would increase over most areas of the globe [68]. According to the U.K. Climate Projections (UKCP09), central estimates are for heavy-rain days (rainfall greater than $25 \mathrm{~mm}$ ) over most of the lowland United Kingdom to increase by a factor of between 2 and 3.5 in winter, and 1 and 2 in summer by the 2080s, under the assumption of a medium-emissions scenario [47]. Also, transient sea level extremes and extreme coastal high waters are expected to change in the future as a result of both changes in atmospheric storminess and mean sea level rise. Trends in extreme coastal high waters across the globe suggest that mean sea level rise, rather than changes in storminess, largely contributes to the increase in sea level extremes. Indeed, the rate of observed sea level rise appears to have increased from the 19th to the 20th centuries, with a mean sea level rising at an average rate of $1.7(1.2-2.2) \mathrm{mm}$ per year over the 20th century, $1.8 \mathrm{~mm}$ per year over 1961 to 2003, and at a rate of 3.1 (2.4-3.8) mm per year over 1993-2003 [8]. On the basis of this trend and observed trends in extreme coastal high-water levels, 
it is very likely that mean sea level rise will contribute to upward trends in the future [61]. Furthermore, despite the great uncertainty, various shortcomings associated with anemometer data, and the inconsistency in anemometer and reanalysis trends in some regions [61], a few studies show growing winter wind storm risk over Europe [56] [16] [17] and particularly an increasing trend in extreme winds over northern Europe [57]. The combination of these factors (i.e., intensification in terms of both frequency and severity of the occurrence of extreme wind and rain events, together with sea level rise) increases the likelihood of flooding along shorelines, which are already experiencing the adverse consequences of impacts such as increased coastal inundation, erosion, and ecosystem losses.

Regardless of the regional variability of climate phenomena on a local scale, the impact of anticipated climate-related changes on coasts are virtually certain to be overwhelmingly negative [52]. This growing hazard will directly affect a large amount of industrial facilities, which have long been located along riverbeds or coastlines to facilitate the transport of materials and to provide easy access to water for industrial processes and waste disposal. For instance, the majority of the nuclear power stations in the United Kingdom are situated on the coast to ensure the availability of cooling water; for the same reason, it is likely that new nuclear facilities will be built in coastal areas. In light of this fact, without appropriate mitigation measures, the potential effects of climate change could mean that these sites will become vulnerable to a greater risk of flooding than if they were located inland [69]. At the same time, the dramatic increase of utilization of the coast registered in the twentieth century is virtually certain to continue through the 21 st century: according to projections, the coastal population could grow from 1.2 billion people (in 1990) to an amount between 1.8 and 5.2 billion people by the 2080s, depending on assumptions about migration [52]. Such growth would contribute to widening the hazardous areas to include an ever-increasing number of communities and technological installations.

These trends clearly suggest a parallel increase of the risk of Natech events and the need for mitigation measures to enhance the reliability of existing systems and to improve the design standards of new facilities. While the perception of the risk posed by Natech events appears to run parallel to the growth of vulnerability, unfortunately the same cannot be said for the theoretical and computational tools available to quantify these kinds of hazards. Not only is knowledge of the interactions between natural events and technological failures still limited [39], but also the current approaches are often based on the adoption of oversimplified models or strong assumptions, which irrevocably affect the reliability of the results. In light of this, the relevance of Natech risk analysis is widely recognized within the scientific community, and further research in this field strongly recommended [14][63].

The reasons behind the unsatisfying results of research in this direction and the subsequent lack of robust tools must be attributed to several bottlenecks, including the following:

- Geographical extent. Natural hazards have the ability to affect large geographical areas and more technological installations simultaneously. Methods for the quantification of the risk 
have to take into account accident scenarios involving failures not only within the facility under study, but also related to the infrastructures whose unavailability can increase the hazard or lower the reliability of the system of interest. Moreover, the wide area of impact of natural events can lead to the occurrence of simultaneous accidents in more facilities, affecting the response and nullifying some mitigation measures. In other words, tools for Natech risk analysis have to be able to model and quantify the risk of simultaneous failures and the domino effect, considering the external environment that the system under study can interact with in case an accident occurs.

- Low probability-high impact. Uncertainty, incompleteness, or lack of information available are issues common to all engineering applications. This is all the more true in the case of low-probability events that are hardly observable: empirical data are generally poor and strongly uncertain, especially with regard to data sets specifically dedicated to Natech scenarios, which are relatively new (even nowadays, a centralized reporting of these events is not provided) [14]. In addition, the randomness of natural events is itself a great source of uncertainty. On the other hand, it is also extremely important to consider the so-called black swan events, meaning unexpected and extremely improbable events of large magnitude and consequence, regarding which very limited or no information is available. Hence, risk analysis has to rely on robust modelling of both epistemic and aleatory uncertainty and on tools able to deal with low probability values.

- Complex networks of dependencies. Technological installations are complex systems that generally involve a great amount of components interacting directly or indirectly with each other. This implies that the failure of each individual component can affect a more-or-less wide range of others, potentially triggering a chain of events and leading to more serious accidents [71]. It is then essential to be able to adequately reproduce these interconnections in order to take into account all the possible simultaneous failure scenarios.

- Interdisciplinarity. The study of Natech events involves a wide variety of experts with different backgrounds (e.g., ranging from engineers to meteorologists to psychologists). The strongly interdisciplinary character of these applications comes from the complex mechanisms of interactions among different environments (e.g., the technological and the natural ones), as well as the importance of taking into account aspects such as the effectiveness of the human response in case of accidents or the probability of human failure. To include coherently the contributions from so many diverse sectors of scientific knowledge, it is necessary to adopt an intuitive framework in terms of both methodology and computational tools that should act as a common ground that is easy to use and understand and far from the jargon of the individual sectors involved. This would simplify the dialogue among experts of different languages promoting the close collaboration of scientists and engineers with industry leaders and policy makers in an interdisciplinary effort to tackle the problem of Natech risk 
reduction and to effectively raise awareness of the risks among the public [39]. The use of a collective language would indeed satisfy the largely recognized need to improve articulation between organizations of different specializations and to promote risk communication and public awareness [14].

Bayesian networks (BNs) meet the requirements highlighted here to a considerable extent [64]. They can be considered as the general case of more common methodologies such as fault tree analysis [26], with respect to which they offer several advantages, at both the modelling and analysis levels. Several restrictive assumptions implicit in the fault tree methodology (e.g., the restriction to Boolean logic) can be avoided, complex dependencies among components can be easily represented, uncertainty can be included in modelling, and both forward and backward analyses are allowed [9].

For the reasons highlighted previously, BNs are considered to be promising tools in the field of Natech risk assessment and have been adopted in the present study.

\subsection{Motivation of the study}

The attention to issues related to nuclear safety is obviously been high, particularly after the Fukushima Daiichi nuclear power plant accident. While most of these concerns are focused on the vulnerability of the reactors themselves, less attention has been paid to the spent fuel facilities [often referred to with the term pools in the United States or ponds in the United Kingdom, and more generally with the acronym spent fuel pond/pool (SFP)], which have the potential to be more vulnerable to failure than the reactor containment building. Furthermore, as recognized by the Nuclear Regulatory Commission [13], even if the likelihood of a zirconium fire due to the exposure of spent fuel is generally very low, the consequences of a similar event would be highly significant. For these reasons, the study of the vulnerability of such installations to external events, such as extreme weather conditions, becomes relevant in view of a more general and accurate risk assessment of nuclear facilities. This kind of analysis implies the use of flexible models that are able to simulate not only the complexity of the system under study, but also different scenarios. For example, assessing the impact of natural hazards on technological installations, the climate change

effect on extreme weather hazards cannot be neglected. Furthermore, a complete evaluation of the risk requires models that are suitable for long-term decision-making support, but also for real-time risk assessment, in order to guide the decision makers even in the case of imminent danger. Finally, as stated by the Nuclear Regulatory Commission [13], SFP risk assessment is complicated by lack of data (e.g., on severe earthquake return frequencies, source term generation in the air environment, SFP design variability, and other factors), hence requiring approaches that can handle a high degree of uncertainty.

In addition to testing the $\mathrm{BN}$ approach in a field not fully explored yet, such as Natech risk analysis, this study aims to provide the first generic model for the quantification of the risk of exposure of the 


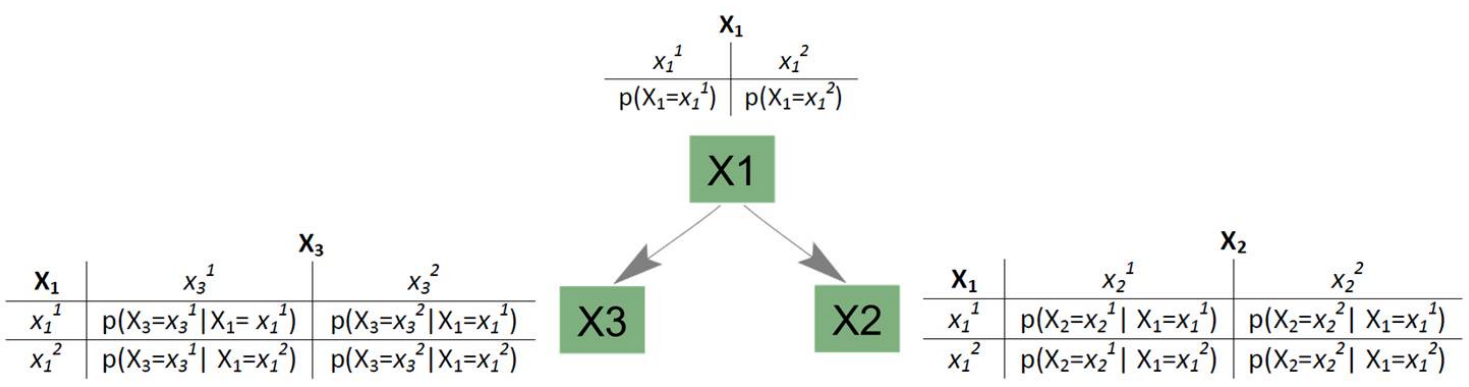

Figure 1: Example of an elementary BN

spent nuclear fuel stored in a fuel pond. Moreover, the model is designed to meet the requirement of flexibility mentioned previously, including long-term considerations. The approach proposed consists of a framework that integrates climate change models in order to assess present and future risks of exposure of spent fuel in the case of flooding of the storing facility. Moreover, thanks also to the BN approach, the model proposed is extremely flexible and can easily be improved when more information is available. Indeed, as shown in the sections later in this paper that describe the sea-wave overtopping event, each node can be expanded, relying on the use of dedicated models and increasing the accuracy of the overall analysis. Finally, as shown in the case study application, the results can be analysed from various points of view, evaluating the risks of several accident scenarios with regard to different time periods. This makes the tool highly attractive for both longterm and real-time risk analysis. In the following section, the theoretical background of BNs is provided. Thereafter, a general model dedicated to the quantification of the risk of exposure of spent nuclear fuel subject to flooding hazard is presented. Next, the application of the model to the case study of the Sizewell B nuclear power station is described. Finally, the results of the study and remarks regarding the advantages and limitations of the adopted approach are widely discussed.

\section{Bayesian Networks}

BNs, also known as belief networks, are statistical models based on the use of directed acyclic graphs for the representation of probability distributions. They provide the factorization of the joint probability distribution associated with an event of interest, exploiting information about the conditional dependencies existing among the variables. This approach relies on a double nature graphically represented by the structure of the network itself, to which quantitative values are associated throughout the introduction of conditional probability distributions. The structure of a $\mathrm{BN}$ consists of a variable number of nodes, each of which represents a random variable of the problem being modelled. The variables should be interpreted in Bayesian terms, or they can have different origins: for instance, they may be observable quantities, unknown parameters, or even mere hypotheses. The nodes of a $\mathrm{BN}$ are connected by edges (commonly represented as arrows) expressing informal or causal dependencies existing among the variables. Only nodes that have 
some sort of dependency are linked, while those that are not joined refer to variables that are conditionally independent of each other. The edges are characterized by directions that are coherent with the causal relationship of the variables connected. With regard to the BN introduced in Fig.1, the node $X_{1}$ is called the parent of $X_{2}$ and $X_{3}$, which are also referred to as its children. Nodes that have no parents are defined as the roots of the network. Generally, on the basis of the Bayes's theorem, the joint probability modelled by any BN with nodes $X_{1}, X_{2}, \ldots, X_{n}$ can be expressed as:

$$
P\left(X_{1}, \ldots, X_{n}\right)=\prod_{i} p\left(X_{i} \mid p a\left(X_{i}\right)\right)
$$

where $p a\left(X_{i}\right)$ refers to the outcomes assumed by the parents of the node $X_{i}$. Then, the joint probability associated with the BN of Fig.1, where all nodes have been assumed boolean only for simplicity purposes (i.e. $X_{i}=\left\{x_{i}^{1}, x_{i}^{2}\right\}, i=1,2,3$ ), is:

$$
P\left(X_{1}, X_{2}, X_{3}\right)=p\left(X_{1}\right) p\left(X_{2} \mid X_{1}\right) p\left(X_{3} \mid X_{1}\right)
$$

In a $\mathrm{BN}$, each node is conditionally independent of its non-descendants given its parent variables, satisfying the local Markov property [60]. The strength of the dependencies associated with each cluster of parent-child nodes is represented by the conditional probabilities mentioned. These can be of different natures according to the structure of the variables concerned. BNs also allow the updating of the marginal probabilities of the variables involved on the basis of new information that might become available. This way, introducing evidence in the model, it is possible to analyse "what if" scenarios, as well as the propagation of the information in the direction of interest. Software packages have been developed that allow the adoption of several algorithms, both exact and approximate, for the computation of inference in BNs. Murphy [49] presents a review of the software packages that are available.

The choice of one approach or the other entails both advantages and disadvantages. Exact inference algorithms (e.g., the junction tree algorithm) are robust and well established in the scientific literature but they restrict the use of probability distributions to the discrete field with the sole exception of Gaussian distributions. In most cases, this implies the necessity to discretize continuous random variables, reducing the quality of the information. On the other hand, the approximate approach allows one to perform the inference on continuous nodes using simulation techniques (e.g., Markov-chain Monte Carlo methods) but it can be either computationally inefficient or have unknown rates of convergence. A complete overview of BNs is provided by Pearl and Russell [55]. Although the establishment of BNs as a field of study and their definition as a complete statistical approach date back to the early 1980s [54], their development has been bound for several years by limitations related to the lack of reliable algorithms and the computational power to compute inference. Conversely, thanks to their unique peculiarities and rapid technological progress in the last several decades, BNs have attracted ever-increasing interest from people in different scientific 
areas. For instance, Weber et al.[70] presented a bibliography review of BN applications in different sectors of applied sciences. The study highlights the increasing use of BNs as a tool for risk analysis: between 2001 and 2008, the number of references per year increased by a factor of 4 . Former studies demonstrate the capabilities of BNs in risk analysis in terms of both the assessment of low-probability events [28] and the modelling of complex systems [34]. Also, the potential of BNs to integrate models and information of different natures, such as human factors, has attracted increasing interest in the literature [11][37].

Finally, limited research proves the great potential of the BN approach in the estimation of natural hazards [64][7].

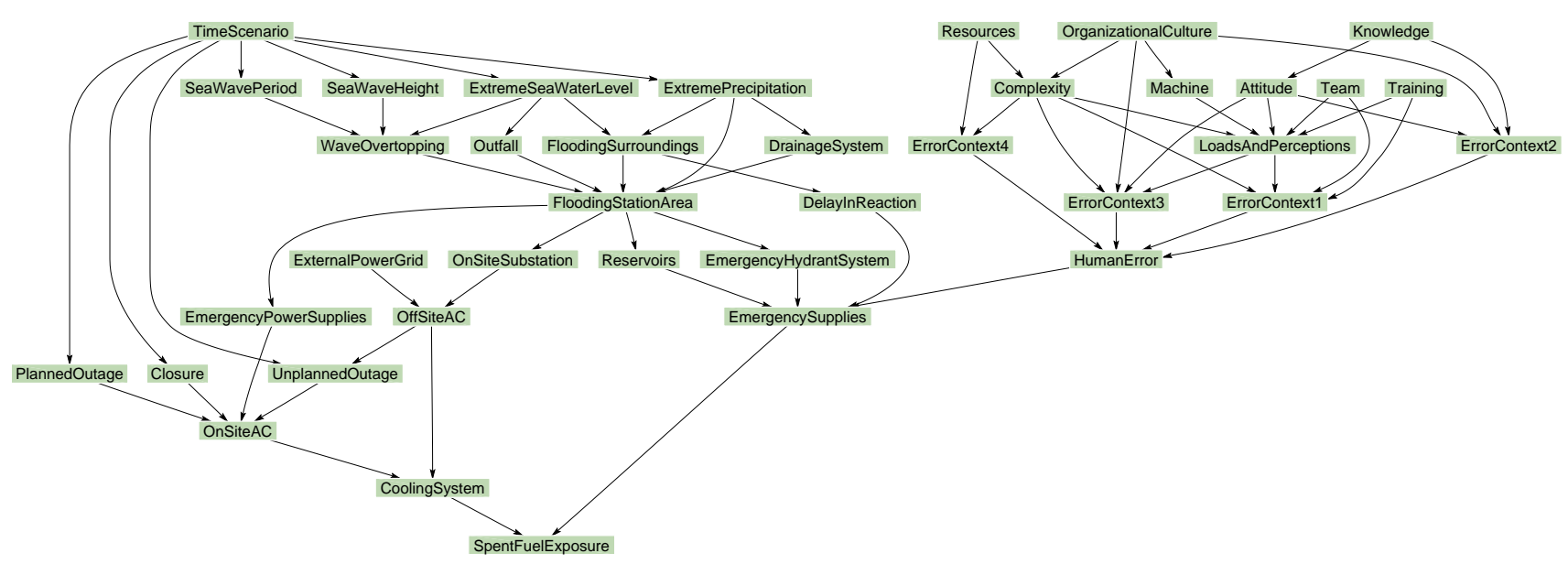

Figure 2: Overview of the BN model proposed for the risk assessment of spent nuclear fuel ponds subject to the risk of flooding

\section{Description of the Proposed Model}

The purpose of the model implemented in this work is to quantify the risk of exposure of the spent nuclear fuel stored in a fuel pond subject to the threat of flooding events, also taking into account the consequences of eventual human error. The network is a general model that can be adopted to compute the vulnerability of any system that is coherent with the hypothesis introduced and described later in this paper. Moreover, given the high adaptability of the model, it can be easily modified to meet the features of facilities differing from the target considered here.

The study focuses only on the flooding hazards, while other sources of risk, such as earthquakes or extreme winds, fall outside the model's area of application. The target chosen is a generic nuclear power station located in a coastal area where the risk of significant tsunamis is generally negligible [33]. Nevertheless, the facility is assumed to be protected by sea defences (such as embankment seawalls commonly provided in rural areas) that are subject to the risk of failure in the case of extreme sea conditions [38]. 
In this study, the contributions of wave overtopping of coastal defences, together with that of heavy rainfall, are considered the main sources of flooding hazard within the station perimeter. The spent fuel management strategy considered for the target facility consists of underwater storage of the fuel rods in a dedicated pond. These are large robust monolithic structures where fuel assemblies are stored in racks that provide spacing for coolant flow: the pools are filled with several additional meters of water above the spent fuel to provide biological shielding [1]. The facility is assumed to be provided with basic equipment such as a drainage system (with a discharge point of the waste stream into the sea; see node Outfall in Fig.2), an on-site electric power substation (to ensure the connection to the national grid), emergency diesels (EmergencyPowerSupplies), emergency hydrants (to make up for the loss of water due to evaporation in the case of failure of the cooling system), and a spent fuel pond cooling system, whose correct functioning is assumed to be bound by the availability of alternating current (AC) power [1].

It is expected that the floods will affect the plant's main and auxiliary supplies (crucial for the correct functioning of the pond), as well as the emergency measures planned to face eventual breakdowns [18]. These can fail due to the unavailability of resources or lack of effective actions due to human error. In this case, the operators who would be supposed to take measures to limit the damages caused by the failure (for instance, manually refilling the pond to ensure the coverage of the fuel) do not act as planned, leading to the same consequences of technical failure (such as the unavailability of reservoirs or emergency hydrants).

The BN proposed (shown in Fig.2) consists of 37 nodes. For the sake of clarity, the description of the model proposed next is organized into three sections, according to the aim of as many different subsets of the network. Since each node of the network is designed to represent a specific event, if not specified otherwise, the terms defining each node and the related event are considered interchangeable from then on.

\subsection{Natural-technological interaction section}

The upper part of the network (Fig.3) aims to model the direct effects of natural events on the nuclear facility and its surroundings. This section discusses nodes either related to weather con-

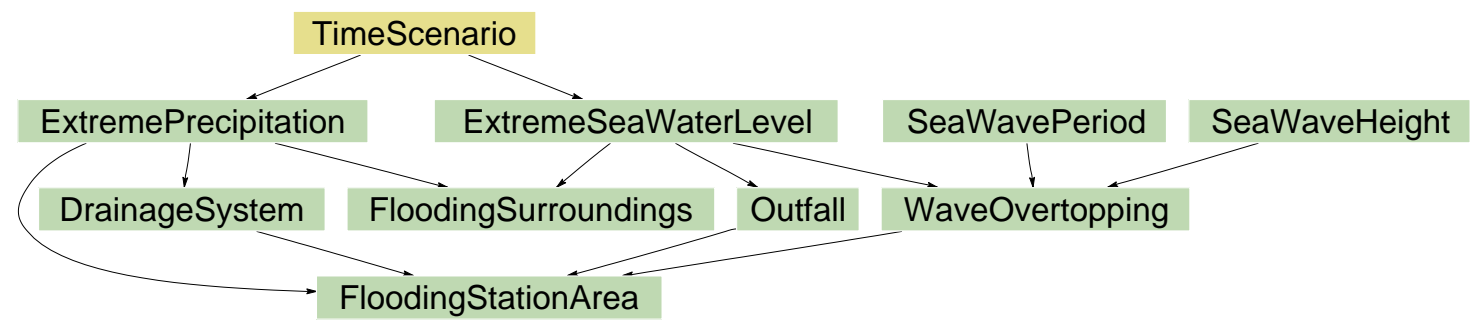

Figure 3: Section of the network modelling the direct effects of natural events

ditions (ExtremePrecipitation, SeaWaterLevel, SeaWavePeriod, SeaWaveHeight) or representing 
failures directly triggered by the natural event (DrainageSystem, FloodingSurroundings, Outfall, WaveOvertopping). Behind the causal links that connect these two series of variables lie three main mechanisms of external flooding:

- River flooding. This contribution is assumed to have the potential to affect the surroundings of the facility, and it is mainly represented by the interaction between ExtremePrecipitation and FloodingSurroundings: an extreme amount of rainfall can lead local water courses to burst their banks, spilling water into the floodplain. Existent models based on local data can be easily adopted to define the causal relationships between the two variables.

- Surface water flooding. It presupposes the impossibility of discharging water from the facility area, causing rainwater to lie or flow over the ground instead of draining away. This can occur as a result of failure of the DrainageSystem, due to exceptionally heavy rainfall (ExtremePrecipitation), or from the unavailability of the Outfall due to extreme sea levels (ExtremeSeaWaterLevel).

- Coastal flooding. It concerns both tidal flooding and sea-wave overtopping of coastal defences. Tidal flooding occurs when low-lying ground is flooded by the sea as a result of the extreme height of the tidal cycle (regardless wave conditions): since nuclear facilities are located at elevations tailored for tide and surge levels [4] this type of contribution is assumed to affect only the surrounding area (FloodingSurroundings). In light of this, the quantification of the risk of coastal flooding for the facility mainly implies modelling the mechanism of discharge of seawater within the station perimeter due to the action of sea waves. This has been realized by integrating the contribution of sea-wave overtopping in the (FloodingStationArea) mechanism. The event (WaveOvertopping) results from extreme sea conditions, which are ExtremeSeaWaterLevel generally, due to the combination of high tide and surges; and SeaWaveHeight and SeaWavePeriod, which under adverse weather conditions can assume severe proportions.

High water levels, represented in the model by the node ExtremeSeaWaterLevel, result from the interaction of tides and storm surges. While the first are originated by astronomical movements, the storm surge consists of a meteorologically driven component of water level generated by synoptic variations of atmospheric pressure and wind [72]. This, therefore, leads to a certain relation between the surge component and the heights of sea waves generated by wind: larger storm surges are expected to correspond to greater values of wind speed. Nevertheless, the correlation results are relatively weak, considering that in a sea level record, the non-correlated tide dominates, with the astronomic tide typically $97-98 \%$ of the total sea level, and rarely less than $80-85 \%$ of the total sea level even during the most extreme events [27]. Hence, as it is only the surge contribution that is likely to be physically associated with extreme wave height under the same meteorological conditions, the assumption of independence between the nodes ExtremeSeaWaterLevel and SeaWaveHeight should not compromise the validity of the assessment. For similar reasons, a certain 
correlation is expected to exist between ExtremePrecipitation and ExtremeSeaWaterLevel as well. Several studies found that the dependence between extreme rainfall and storm surge is statistically significant and needed to be taken into account for flood risk estimation, although spatial variability of the dependence strength was observed [66]. In this case, though, the consideration of general sea level (in most cases dominated by astronomical tide) leads to weaker dependence values compared to the adoption of storm surge estimates; furthermore, little is known about the factors behind such dependence, nor of the degree of variability of dependence strength over a large geographic area [73].

In the absence of a direct causal relation between the variables, it is not possible to represent the correlation in the network; nevertheless, this limitation of the method is mitigated by the weakness of the correlation values among the variables involved, which is expected to have a negligible influence on the overall result of the analysis. The overall combination of the flooding dynamics considered can lead to the accumulation of water within the perimeter of the facility, event represented by the node FloodingStationArea. No internal failures (such as the damage of pipes or reservoirs) are taken into account as sources of flooding in the model. This part of the network also embraces improperly causal relations: the node TimeScenario, as the name suggests, allows analysis to run with regard to a particular time interval of choice. Introducing evidence in the node, hence selecting the time scenario of interest, it is possible to take into account the influence of climate change on natural events. As Fig. 2 shows, climate change forecasts are considered in terms of sea level rise (represented by the edge pointing to the ExtremeWaterLevel node) and intensification of precipitations. Also, extreme wave conditions depend on the time period considered: previous studies [40] have shown that climate change may have a significant impact on sea-wave characteristics, even if considerable variation in projections can arise from the different climate models and scenarios used to force wave models, which reduces the confidence in the projections already lowered by the small number of studies, lack of consistency of the wind projections between models, and limitations in their ability to simulate extreme winds [61].

\subsection{Internal failure section}

According to the BN model proposed, the event of exposure of the spent nuclear fuel is bound by the availability of either cooling systems or emergency supplies. Only if both these subsystems are out of order is the SpentFuelExposure event (Fig.4) assumed to occur. As mentioned previously, the cooling system is expected to fail if no electric power, either generated on site $($ OnSiteAC) or supplied to the station from the external grid (OffSiteAC), is available. Hence, station blackouts are considered as the main safety issue for the correct functioning of the spent fuel pool, since many safety systems required for heat removal depend on AC power [5]. The failure of on-site generation can be attributed to power station outages, whether planned (e.g., refuelling or decommissioning) or unplanned (e.g., emergency reactor shut-down); the failure of emergency power supplies (EmergencyPowerSupplies) is also a precursor of station blackouts. Indeed, nuclear 


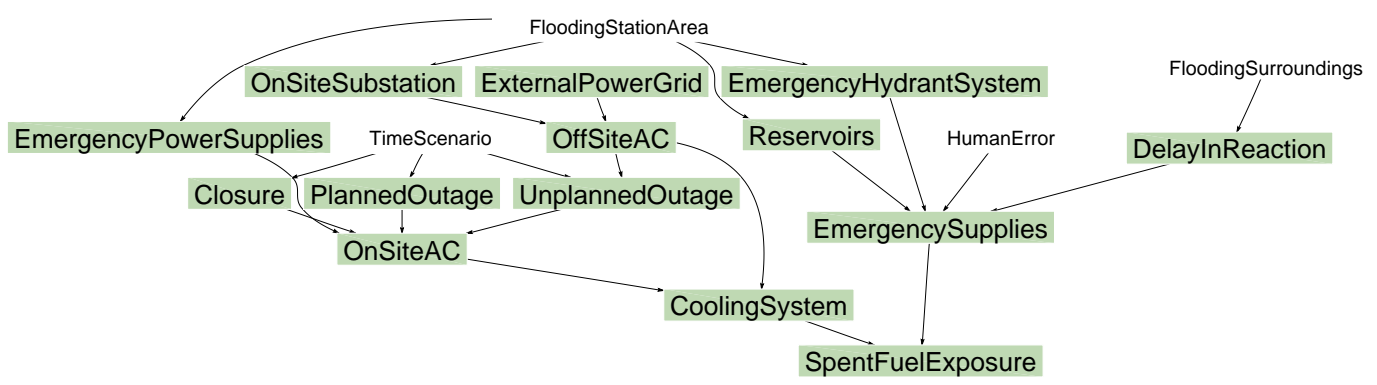

Figure 4: Section of the network modelling internal failures

power plants worldwide have a configuration of emergency power supply systems (typically emergency diesel generators) that include at least two redundant trains of safety buses, each powered by an emergency diesel generator that replaces the regular power supply or off-site power should it become unavailable [32]. Coherently, the failure of EmergencyPowerSupplies is assumed to lead to a station blackout in case of loss of OffSiteAC. If both the outage and the failure of emergency diesels occur, no power generation is assumed to be available on site.

Normally, the interface between the plant's main generator and the electrical grid is formed by the OnSiteSubstation, which provides reliable off-site power for the nuclear station under all operating and shut-down conditions. For example, if power generation is interrupted, the power supply automatically transfers to the off-site grid. If that is not supplying suitable power (e.g., unacceptable voltage), the buses are reenergized by fast-starting emergency diesel generators [41]. In light of this, the failure of the on-site electric substations and connections (OnSiteSubstation) can cause loss of power from the external network. This can also be triggered by a generic loss of external power grid, in which case the nuclear plants involved in the blackout are required to shut down safely (UnplannedOutage), according to procedures [43]. Failure of the emergency power supplies would seriously hinder the ability of the plant operators to carry out the required safety functions [41]. This is taken into account in the model by the node EmergencySupplies, which refers to the lack of effective actions on the pond in the case of unavailability of the cooling system. This kind of intervention involves both technological and human aspects: spent fuel ponds are provided with a source of high-purity water (generally the refuelling water storage tank for pressurized water reactors and the condensate storage tank for boiling water reactors) to make up for the loss of water due to evaporation in the case of cooling system loss. Plants also have alternative methods to provide make-up if normal make-up is unavailable, and may include the service water system and the fire water system, which can require the intervention of operators [1]. The possible loss of water inventory is taken into account in the model through the node Reservoirs, while the possible failure of the fire water system is represented by the node EmergencyHydrantSystem. The occurrence of human error (HumanError) is considered to nullify or prevent the action leading to a lack of intervention by the operator, with consequences similar to that of a EmergencyHydrantSystem failure. The large volume of water in the pond ensures a significant thermal inertia, generally slowing any 
accident progression and giving respite for actions from the outside (e.g., use of fire tenders). Only if this intervention fails as well (DelayInReaction) is the failure of EmergencySupplies assumed to occur.

This section of the network is connected to the overall model through four nodes: FloodingSurroundings, FloodingStationArea, TimeScenario, and HumanError. The first two belong to the upper part of the network previously discussed and affect the system in similar ways: flooding near the station has the potential to affect the only road of access, and then to make the rescue from the outside impossible; likewise, the accumulation of water inside the facility can affect a wide range of other subsystems, such as emergency supplies or electric transformers. Also the node TimeScenario belongs to the first section but, as mentioned before, it does not represent a proper event since the links that it shares with other nodes have no causal meaning. The connection between this node and PlannedOutage aims to take into account the possible decommissioning of the nuclear power plant in future scenarios.

Finally, the HumanError event refers to the lack of action by the operators and is modelled according to Groth and Mosleh [25] by a third part of the overall network, described next.

\subsection{Human Error section}

From the evaluation of past events and accident scenarios involving spent fuel pools, human error has been reported as one of the most common root causes [1]. Even if none of the reported events resulted in severe accidents (many of them had only negligible consequences on the spent fuel), this highlights the importance of including operator performance in the analysis. Although several methodologies for human reliability analysis have been proposed in the literature, none of them has ever reached a general consensus.

Commonly, human error has been modelled on the basis of probabilistic concepts, assuming all probabilities to be precise [59]. Nevertheless, the probabilistic approach has shown a limitation on the quantification of qualitative aspects of human error and the complexity of attributes from the circumstances involved, leading to investigate methodologies based on a fuzzy logic approach, which is expected to better represent the human interacting system's reliability [35]. However, research in this direction is still limited with regard to applications to the nuclear industry [15]. More traditional and common approaches are based on the use of precise numerical factors aiming to capture the influence of given specific working conditions or task situations on human activities. For instance, performance-influencing factors (PIFs) are largely used as causes or contributors to unsafe human actions in event analysis to predict human behaviour and cognitive processes [36]. A BN approach to human reliability represents a good compromise approach to integrating limited data and expert judgement without losing the robustness of well-known and largely used approaches [25]. In this study, the BN model proposed by Groth and Mosleh [25] to quantify the probability of human error in case of significant incidents at a nuclear power plant has been integrated into the overall framework. The approach suggested in the study and shown in Fig.5 integrates PIFs 
and their interdependencies in a BN framework. Nine of the nodes belonging to this section (Resources, OrganizationalCulture, Knowledge, Team, Training, Complexity, Machine, Attitude, and LoadsAndPerceptions) refer to as many groups of PIFs, while the four ErrorContext nodes aim to capture the interrelation among different factors and correlations among nodes not linked by direct causal relationships. Each of these four nodes acts as a precursor of the HumanError event, to which all of them contribute with different weights. For further details regarding the approach refer to Groth and Mosleh [25].

This part of the network is linked to the rest of the model through the causal dependency between the nodes HumanError and EmergencySupplies, as argued in the previous section. An accurate approach should take into account other aspects, such as the consequences of flooding on the availability of suitable tools (Resources) or the effect of downsizing (in the case of decommissioning) on the work team (Team). However data limitations preclude this kind of development of the model for now. Further study in this direction is strongly advisable but beyond the scope of this work.

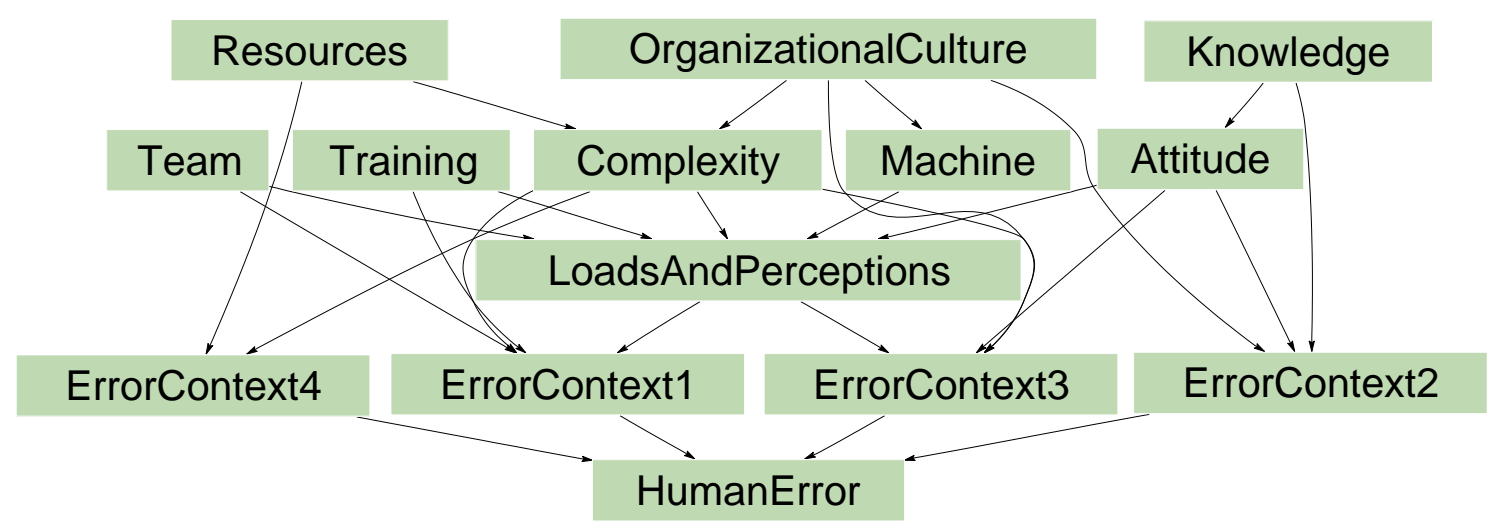

Figure 5: Section of the network modelling human failures

\section{A case study: Sizewell B nuclear power station}

The nuclear power plant of Sizewell B (Fig.6) in East Anglia, United Kingdom, operated by EDF Energy, has been selected as a real-world case study for the application of the proposed BN model. There are several reasons behind the choice of this station: first, the location is particularly interesting since, according to the flood maps provided by the U.K. Environment Agency [2], the surrounding area is subject to risk of flooding. Next, EDF's strategic target is to extend the operational life of the installation, postponing the decommissioning date from 2035 to 2055 [30]; it is then of particular interest to evaluate the impact of climate change on the risks to which the facility is subject. 


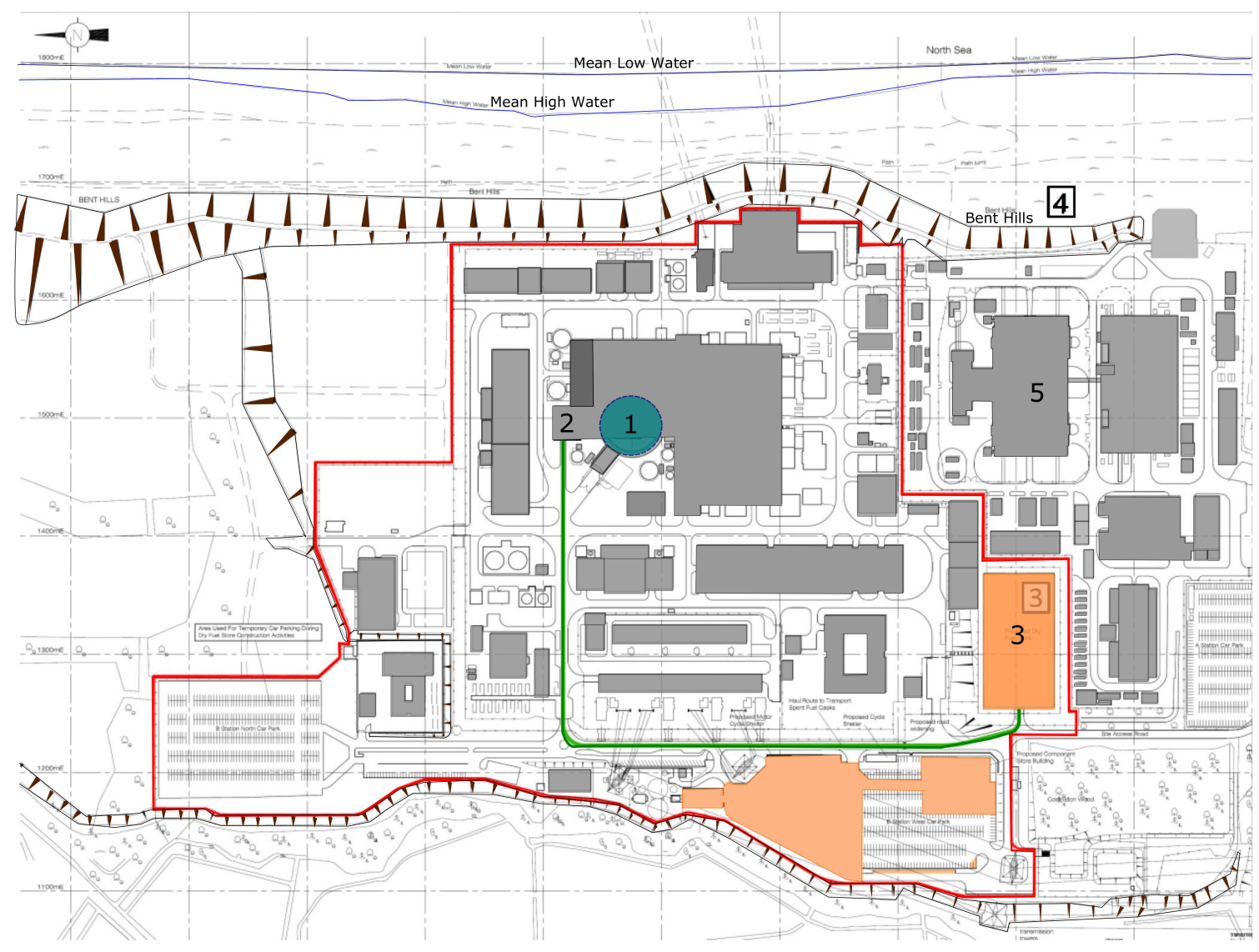

Figure 6: Simplified layout of the Sizewell nuclear site with reactor building (1), fuel building (2), and dry fuel cask (3); at the east of the site are located the so-called Bent Hills (4), and to the west the Sizewell A power station (5)

Moreover, unlike British Magnox and advanced gas-cooled reactor (AGR) stations, in which the spent fuel is located on site only for short periods and then transferred to the reprocessing facility of Sellafield, the management strategy adopted for Sizewell B involves long-term on-site storage under water [22]. Furthermore, the current rate of accumulation and current safety restrictions suggest that full capacity of the on-site pond will be reached by 2015. Finally, the construction of a new dry fuel storage system (started in January 2013 to guarantee further capacity) and the aim to build a new power plant located on land next to the current Sizewell B station make this case study more attractive in view of further developments and applications. This section aims to provide an overall description of the facility under study, as well as of the related numerical implementation. Finally, the results obtained by the inference computation on the network are introduced and analysed. 


\subsection{Description of the facility}

The Sizewell B power plant is built on a plateau $6.4 \mathrm{~m}$ above ordnance datum (AOD) on the coast of East Anglia in the county of Suffolk. It shares a site of 97 ha with the Sizewell A station (which is no longer operating) on the southern side. The area to the east of the station consists of a series of sand dunes that gradually slope down to the seashore, covering a width of approximately $100 \mathrm{~m}$. These ridges, commonly known as the Bent Hills, have been remodelled to provide a 10-m-high sea defence embankment along the east boundary of the site. The land surrounding the station to the north and west is swampy and subject to the risk of flooding. Nevertheless, due to the major elevation of the nuclear island with respect to its surroundings, floods in this area are not expected to represent a direct hazard to the station. The site access road is located at an elevation of $3.5 \mathrm{~m}$ AOD.

Built between 1988 and 1995, the power plant includes two main turbine generators and a single reactor based on a Westinghouse standard, four-loop, pressurized water design. The initial design was modified, mainly in terms of capacity and redundancy of safety system, in order to fulfil U.K. requirements. The station supplies to the national grid 1,198MW, approximately equal to $3 \%$ of the United Kingdom's power needs. The on-site electric substation is connected to the external grid at three separate $400 \mathrm{kV}$ points (two at Bramford, one at Norwich, and one at Pelham) and provides a connection with the external network for the import and export of power.

Adjacent to the reactor building, the fuel building accommodates the pond, where both new and used fuel are stored underwater [6]. The pool consists of a stainless steel-lined reinforced cavity where the fuel assemblies are located at a depth of water adequate to guarantee the coverage of the fuel for $24 \mathrm{~h}$ in case of total loss of the cooling system. The latter consists of a primary ultimate heat-sink (seawater) and a reserve ultimate heat-sink (air-cooling system), which ensure the thermal exchange required for the pumped flow. The availability of $\mathrm{AC}$ power on site binds the working order of the cooling system in the fuel facility. All the buildings on the nuclear island are provided with fire doors that can act as flood barriers up to a water depth of $1 \mathrm{~m} \mathrm{[20].} \mathrm{According}$ to a report by Magnox [42], a reservoir with a maximum water level of $13.9 \mathrm{~m}$ AOD and an invert level of $6.9 \mathrm{~m}$ AOD is located on site.

\subsection{Numerical Implementation}

The inference on the network for the Sizewell B application has been computed using the Bayes net toolbox for MATLAB [48][45] and adopting the well-known junction tree inference algorithm. As previously mentioned, the use of exact inference methods (such as the junction tree algorithm) can lead to the impoverishment of the information available due to the need of discretization and, in some cases, can affect the congruence of the result. As already highlighted for a previous version of the model [67], the limitations discussed for this application have faced a particular significance with regard to the modelling of the sea-wave overtopping mechanism. In light of this, the approach 
suggested by Straub and Kiureghian [65] was applied to a small subset of the section (namely, the nodes SeaWavePeriod, SeaWaveHeight, ExtremeSeaWaterLevel, WaveOvertopping) in order to be able to take continuous distributions into account without abandoning exact inference methods. This is possible thanks to the use of structural reliability theory to enhance BN models. Indeed, the approach allows the computing of relations among continuous variables, reducing the inference problem to that of a traditional $\mathrm{BN}$ without losing information or accuracy.

The numerical implementation of the case study introduced in this part of the discussion is organized into three subsections: the first two refer to the natural-technological interaction section (or top section), addressing the computation of the WaveOvertopping node briefly introduced here and the data source of the climate change scenarios embraced. The last section is dedicated to the description of the bottom part of the network, providing details about the inputs adopted for the internal failure section. The human error section of the model is not discussed here since, in the absence of additional data, the numerical values provided by Groth and Mosleh [25] have been introduced without further updating. Please refer to the original study for more details about the numerical values adopted in the implementation.

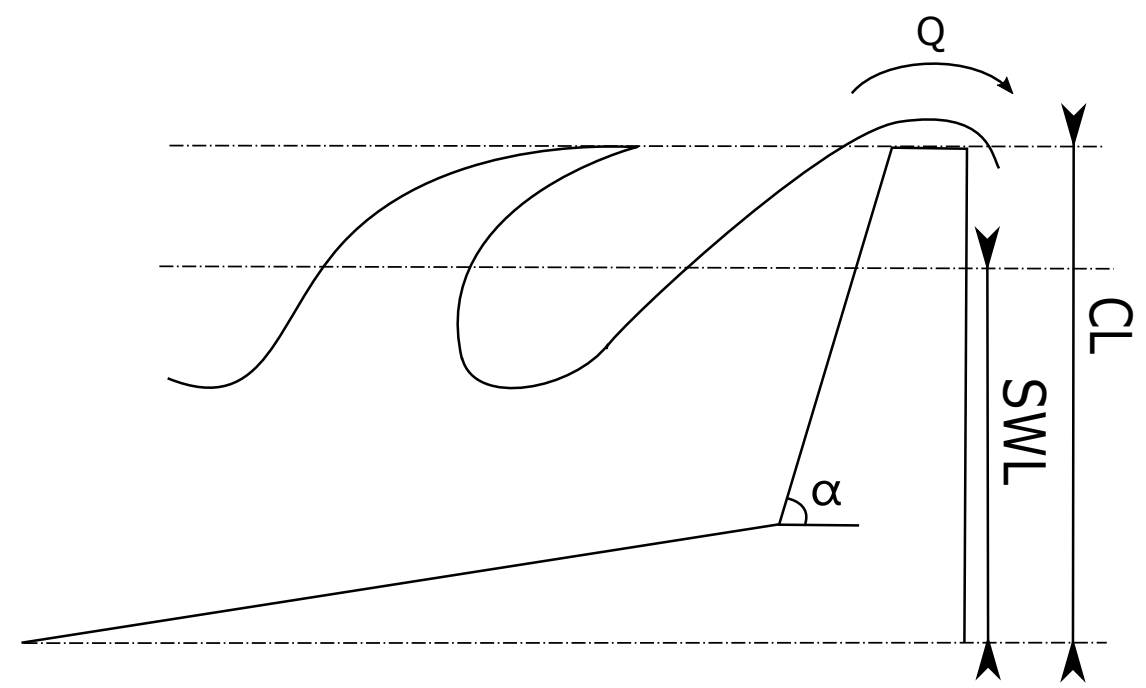

Figure 7: Scheme of the sea-wave overtopping mechanism; CL refers to the crest level of the seawall; SWL the still-water level; and Q the overtopping rate

Top section: wave overtopping of sea defences As shown in Figs. 2 and 3, the WaveOvertopping node has three parents: ExtremeSeaWaterLevel, SeaWavePeriod, and SeaWaveHeight. The return values related to the first of the three events for the coast of Sizewell have been provided by U.K. Environment Agency [3] and updated using the sea level rise projections specified in the next subsection. On the contrary, no probability values or model for SeaWavePeriod and SeaWaveHeight are available in the existing scientific literature: inputs for these two nodes have been computed starting from historical records provided by CEFAS [23]. The available data have been recorded using a directional waverider buoy located off the coast of Sizewell and moored at a water 


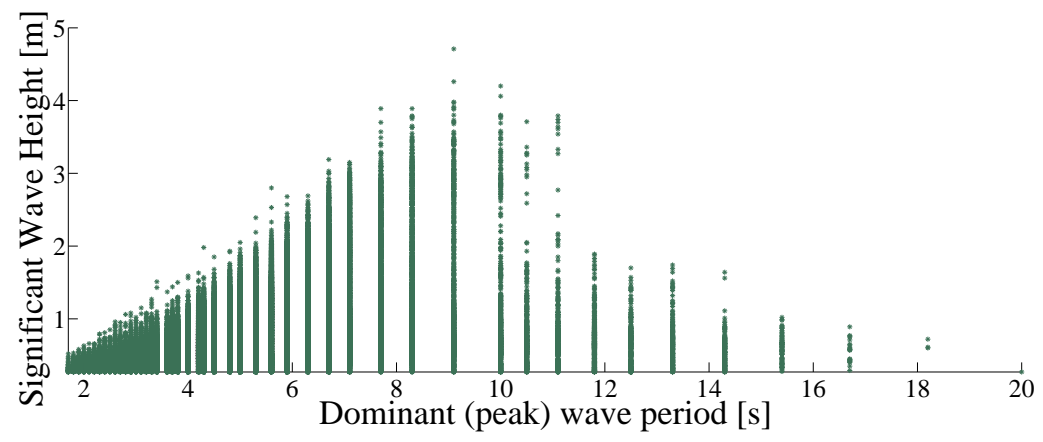

Figure 8: Scatter diagram of significant wave height and peak wave period data

depth of $18 \mathrm{~m}$. Records cover a time interval of more than six years (from February 2008 to August 2014) for a total of almost 90,000 valid measurements. The data refer to the significant wave height (mean wave height of the highest third of the waves recorded) and wave peak period (wave period corresponding to the peak of the incident wave spectrum) and are shown in the scatter diagram shown in Fig.8. It has been fitted into generalized extreme value probability distributions (Fig.9 for the related wave significant height statistical model) using the maximum-likelihood estimation method [see Appendix]. The optimized values obtained for the parameters of the significant wave height and peak period probability distributions are presented in Table 1. The adoption of this type of distribution is justified by the need of predicting return values for extreme wave conditions and then to extrapolate well beyond the range of the available hindcasts [10]. As is possible to see in Fig.9 with regard to the significant wave height data, a minimal loss of accuracy in the first part of the domain is balanced by a good representation of the measurement trend in the region of maximum interest for this study, which means the right side of the wave height domain to which corresponds a higher risk of overtopping.

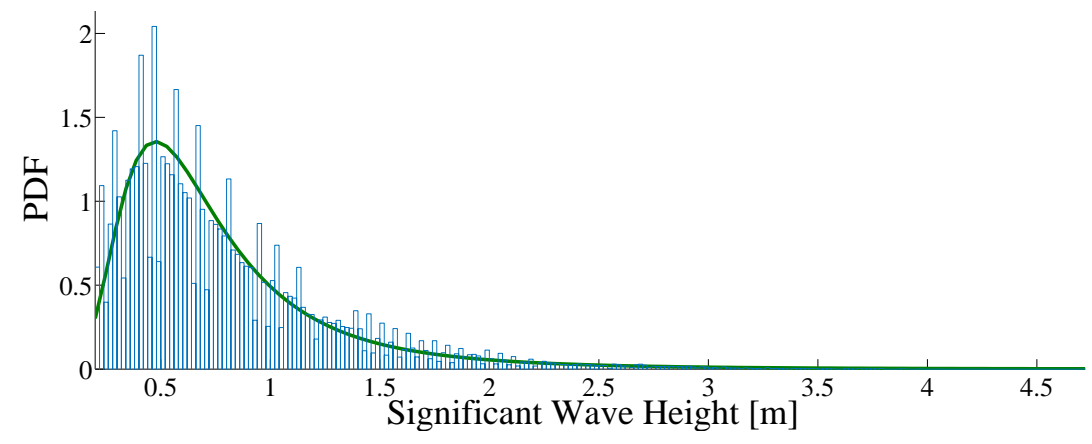

Figure 9: Generalized extreme value model of the wave significant height probability distribution

As opposed to its parents, neither discrete probability values nor historical data are available for the event WaveOvertopping; hence, the conditional probability values of the node must be computed by means of mathematical models.

The WaveOvertopping event is assumed to occur when the amount of seawater overcoming the sea defence exceeds the admissible wave overtopping rate (equal to $0.0466 \mathrm{~m}^{3} / \mathrm{s}$ per unit length of 
Table 1: Parameters of Generalized Extreme Value Distributions Computed with Maximum Likelihood Estimation

\begin{tabular}{lcc}
\hline Parameter & WaveHeight & WavePeriod \\
\hline Shape Parameter & 0.26803 & 0.00513 \\
Scale Parameter & 0.28039 & 1.45702 \\
Location Parameter & 0.53984 & 4.62444 \\
\hline
\end{tabular}

the seawall for this application), according to the mechanism shown in Fig.7. According to the probabilistic model suggested by Hedges et al. [29], waves overcome the sea defences when the following condition is verified:

$$
0 \leq \frac{(C L-S W L)}{r C H_{s}}<1
$$

where $C L=$ crest level of the seawall; $S W L=$ still-water level (average water surface elevation at any instant including the effect of tides, storm surges, and long-period seiches); $r=$ seawall slope roughness; $H s=$ significant wave height; and $C=$ ratio of the maximum run-up [maximum vertical extent of wave uprush on a beach or structure above the still-water level [62]] to the significant height of the incident waves and can be expressed as a function of the surf similarity parameter $\xi_{p}$, given by the equation:

$$
\xi_{p}=\frac{\tan (\alpha)}{\sqrt{2 \pi H_{s} / g T_{p}^{2}}}
$$

where $T_{p}=$ peak wave period. Hence, for given seawall features, such as the slope roughness and inclination $(\alpha)$, the probability of excedance of the admissible wave overtopping rate $Q$ can be computed as $P(Z \leq 0)$ where $Z$ is expressed, according to Hedges and Reis, as

$$
Z=Q-A \sqrt{g\left(C H_{s}\right)^{3}}\left[1-\frac{C L-S W L}{r\left(C H_{s}\right)}\right]^{e_{B} B}
$$

where $g$ refers to the gravitational acceleration, $A$ and $B$ to empirical coefficients of the model dependent on the inclination of the seawall [58] and $e_{B}$ to a a parameter that represents the scatter about the line of perfect agreement between the predicted and measured values of the mean discharge.

It is clear that discretizing the WavePeriod and WaveOvertopping nodes would affect the credibility of the analysis and the effectiveness of the model adopted to compute the conditional probabilities of the event WaveOvertopping. Moreover, as it is possible to see from the scatter diagram in Fig. 8 and the graphs in Fig.10, the two series of data related to the peak wave period and significant wave height are correlated to each other. To ignore such a correlation would result in the loss of physical significance of the model, including in the analysis pairs of values for $T_{p}$ and $H_{s}$ incompatible with the natural limits associated to wave conditions (e.g., very high significant heights and very low peak period, or areas of the domain with no records available, as shown in Fig.10). The 

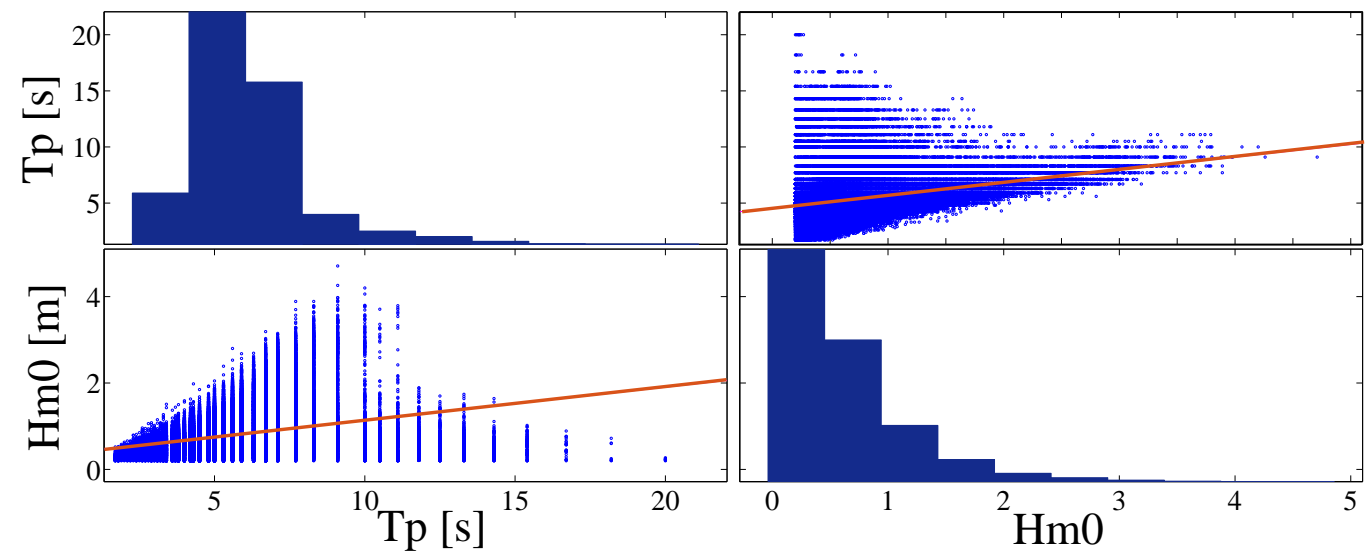

Figure 10: Analysis of the correlation between significant wave height $(\mathrm{Hm} 0)$ and peak period(Tp)

adoption of a structural reliability approach to compute the input of the WaveOvertopping node is the solution chosen in this study to overcome these issues: it allows exploitation of all the accessible information (then avoiding the discretization of the continuous distributions), as well as using linear factors to represent the correlation among variables, which are hardly characterizable otherwise. On the other hand, this procedure excludes the SeaWavePeriod and SeaWaveHeight nodes from the original $\mathrm{BN}$ and then from the inference computation: the results of the analysis are stored in the WaveOvertopping node, whose conditional probabilities are updated according to the results. To calculate the conditional probability of exceedance of admissible wave overtopping rate (WaveOvertopping), given the state of the seawater level, requires as many analyses as many are the possible states of the node ExtremeSeaWaterLevel. Hence, the result of each analysis corresponds to the probability of wave overtopping in the case in which the seawater level falls in a particular interval of values according to the outcome states of the node ExtremeSeaWaterLevel. The probabilities estimated this way were then introduced in the new conditional probability table of the node WaveOvertopping, which in the reduced BN obtained through this approach has ExtremeSeaWaterLevel as the only parent node.

The reliability analysis based on the probabilistic model of Hedges et al. [29] described above has been performed using Monte Carlo simulations in the general-purpose software OpenCossan OpenCossan [53]. In the implementation of the model, all the waves have been considered normally incident to the seawall and no integration with offshore, near-shore wave transformation models has been considered, resulting in a strongly conservative approach. Conversely from what suggested for the general model, no link has been considered between TimeScenario and the wave condition nodes. Indeed, previous studies on the impact of sea level rise and climate change on wave climate along the coast of East Anglia [12] have shown that the climate change scenario selected leads to a significant increase of extreme wave heights only in the northern part of the region but has only very little impact on the southern domain of the study, which interests the Sizewell area (e.g., projected change for the 50-year return significant wave height in the region are be- 
tween 0 and $-0.1 \mathrm{~m}$, referring to the period between 2069 and 2099). Moreover, the same study found offshore extremes (considered in this study) were not modified by sea level rise, which was insignificant compared to the offshore water depths. Simplified assumptions have been made on the composite seawall of the station, which has been considered as an equivalent uniform, smooth, and impermeable slope. Moreover, as suggested by Hedges et al. [29], the inclination of the seawall has been considered as normally distributed with mean 0.05 (corresponding to an inclination of 1:20) and standard deviation of 0.1. The generalized extreme value distributions described in Table 1 have been adopted for the peak wave period and significant wave height. In order to avoid unrealistically wave conditions, a Pearson correlation coefficient of 0.29 (represented by the continuous line in Fig.10) between the two variables has been computed from the respective series of measurements available. This linear factor accounts for the fact that higher waves tend to have longer periods, as shown by the data. The results of the reliability analysis are shown in Table 2 . As foreseeable, the conditional probability associated to the node WaveOvertopping grows along with the seawater level.

Table 2: Conditional Probability of Exceedance of the Overtopping Admissible Rate Given Different Values of Seawater Level

\begin{tabular}{lc}
\hline Sea Water Level & WaveOvertopping \\
\hline Over 5 m Above Ordnance Datum & $3.262 \cdot 10^{-04}$ \\
Below 5 m Above Ordnance Datum & $4.910 \cdot 10^{-05}$ \\
\hline
\end{tabular}

\subsubsection{Top section: climate change scenarios}

The TimeScenario node contemplates multiple outcome states, allowing three different time scenarios to be taken into consideration: the first related to the current conditions, the second to those estimated for the year 2055, assuming that the station is still in operational order. Finally, the third scenario involves the presence of spent fuel stored and the production of electric power on site is limited to emergency diesels. The assumptions related to the three time scenarios are summarized in Table 3. All the predictions related to climate change and adopted in the case study refer to Table 3: Characterization of the Time Scenarios Adopted in This Study

\begin{tabular}{lcc}
\hline & Year of Reference & Station State \\
\hline Scenario 1 & 2015 & Operational \\
Scenario 2 & 2055 & Operational \\
Scenario 3 & 2099 & Closed \\
\hline
\end{tabular}

a medium-emission scenario called SRES AlB, according to the Intergovernmental Panel on Climate Change classification. The greenhouse gas emission forecasts associated with this scenario are based on the assumption of a future world with very rapid economic growth, a global population that peaks in midcentury and declines thereafter, and the rapid introduction of new and 
more efficient technologies inspired by the balanced use of fossil and non-fossil energy sources [51]. Projections [46] associated with this background have been adopted to update the extreme seawater level return period values provided by the Environment Agency. As shown in Fig.11, the results show the effect of sea level rise on the return values of the seawater level, which is expected to increase of $0.301 \mathrm{~m}$ in 2055 and $0.659 \mathrm{~m}$ in 2099, in light of the emission scenario embraced. Regarding the quantification of risk for extreme precipitation events, return period values from

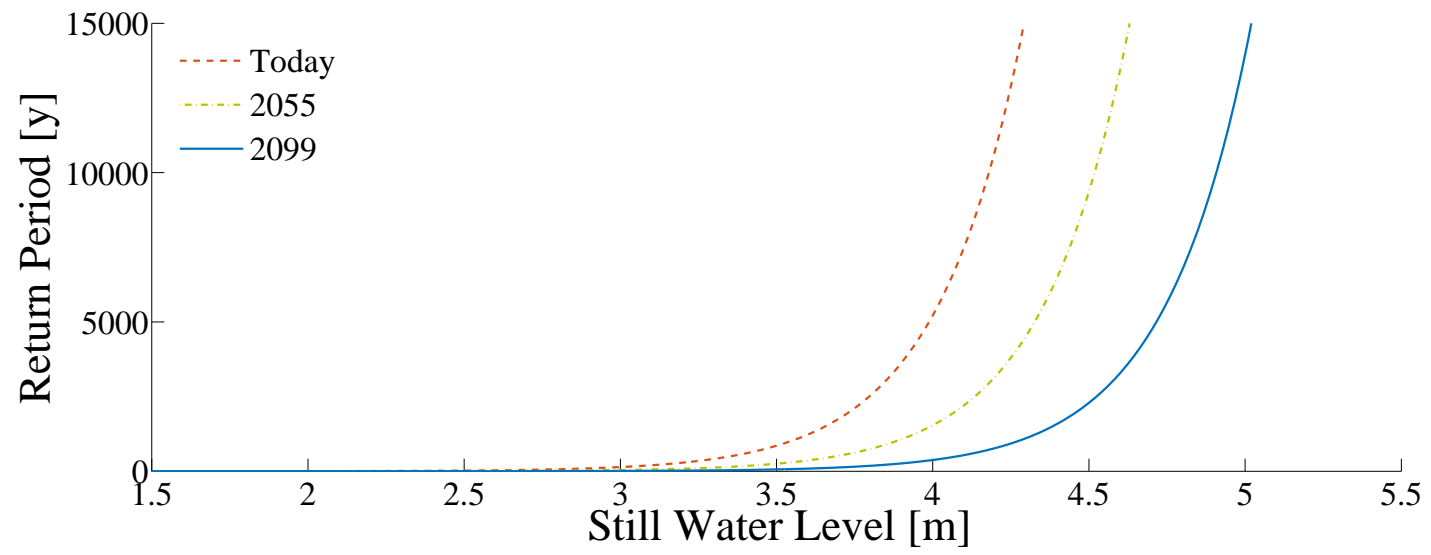

Figure 11: Return period curves for extreme sea water level

previous studies have been adopted [24]. Also, in this case, it is possible to note the growth in frequency and intensity of the extreme precipitation events, along with the three time scenarios of reference. Moreover, as shown in Fig.12 as well as by the results in Table 4, the difference between the precipitation amount in the three scenarios tends to grow for higher return periods, going from $31 \mathrm{~mm} / \mathrm{d}$ of difference between Scenarios 1 and 3 for the 500 -year return period to $44 \mathrm{~mm} / \mathrm{d}$ for the 1,500-year return period. The state of the ExtremePrecipitation node directly determines

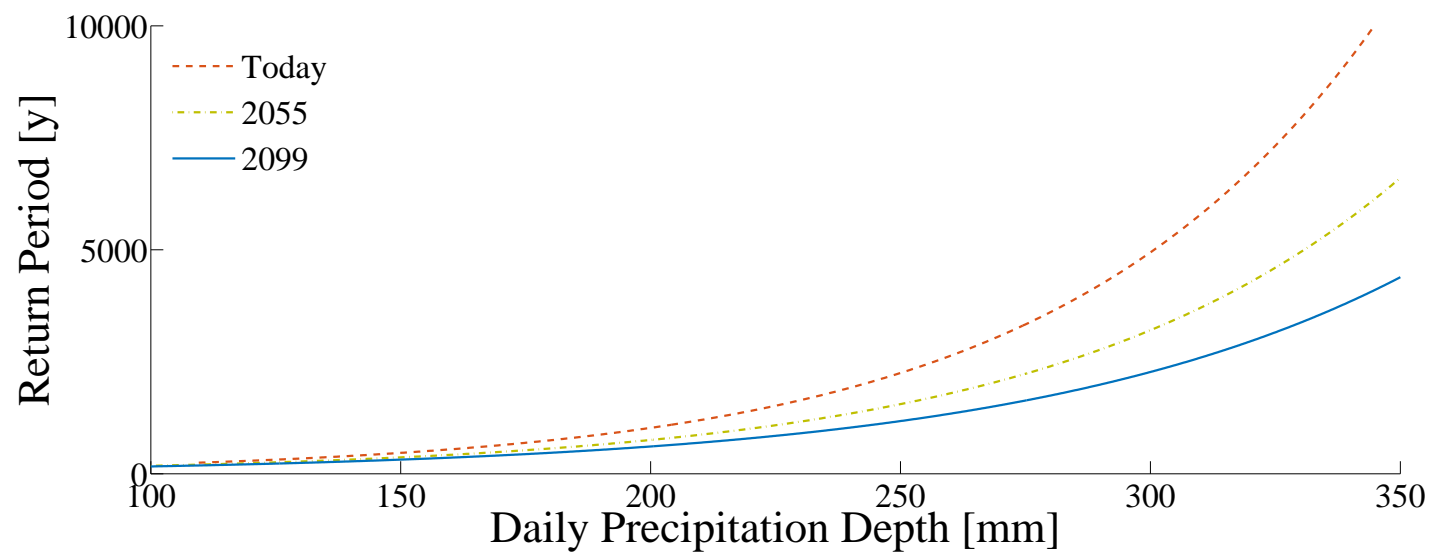

Figure 12: Return period curves of daily extreme precipitation for the three scenarios considered the outcome of DrainageSystem, which is assumed to fail when the design basis of $200 \mathrm{~mm} / \mathrm{d}$ is overcome. Similarly, the failure of the outfall, as well as the flooding of the area surrounding the 
Table 4: Extreme Precipitation Return Periods for the Three Time Scenarios Considered

\begin{tabular}{lccc}
\hline Return Period & Scenario1 & Scenario2 & Scenario3 \\
\hline $500 \mathrm{y}$ & $154 \mathrm{~mm} / \mathrm{d}$ & $171 \mathrm{~mm} / \mathrm{d}$ & $185 \mathrm{~mm} / \mathrm{d}$ \\
$1000 \mathrm{y}$ & $198 \mathrm{~mm} / \mathrm{d}$ & $226 \mathrm{~mm} / \mathrm{d}$ & $237 \mathrm{~mm} / \mathrm{d}$ \\
$1500 \mathrm{y}$ & $224 \mathrm{~mm} / \mathrm{d}$ & $247 \mathrm{~mm} / \mathrm{d}$ & $268 \mathrm{~mm} / \mathrm{d}$ \\
\hline
\end{tabular}

station, are supposed to occur when the still-water level is higher than $5 \mathrm{~m} \mathrm{AOD.} \mathrm{In} \mathrm{this} \mathrm{case,} \mathrm{the}$ seawater is expected to overcome the coastal embankment impeding the use of the access road (located at $3.5 \mathrm{~m}$ AOD). Finally the FloodingInTheStationArea event is assumed to occur when the depth of water accumulated in the nuclear island (neglecting the topological set-up of the area) is equal to or higher than $1.15 \mathrm{~m}$, design basis for the fire barriers, which are expected to act as flood barriers up to that value.

\subsubsection{Bottom section}

Unlike the upper part of the network, the conditional probabilities of the internal failure section are quite homogeneous in terms of sources of data. The majority of them, indeed, have been collected from the scientific literature available. The probability of failure for the node EmergencyPowerSupplies is assumed to equal 1 when the station is flooded and $3 \cdot 10^{-09}$ (combination of the failure probabilities of the four emergency diesels) otherwise [19]. The four engines have been considered independent because each of the four trains is capable of supplying its selected loads independent of the other three systems [20]. Likewise, the probability of failure of the external grid (ExternalPowerGrid) has been calculated as the product of the failure rates of the three offsite substations to which the power plant is connected [50]. Also, in this case, independence has been assumed and the hypothesis justified by the geographical distance of the three sites [20]. The rate of planned and unplanned outages has been calculated on the basis of the refuelling schedule and the frequency of past events, both derived from EDF documentation [21]. Also, the failure rate of emergency hydrant systems has been collected from previous research [31]. Table 5 shows the references related to the nodes of the bottom section for which the probability values have been collected or derived from the available literature.

Table 5: References for the Input of Bottom Section Nodes Deduced from Previous Scientific Research

\begin{tabular}{lc}
\hline Node & Reference \\
\hline ExternalPowerGrid & {$[50]$} \\
EmergencyHydrantSystem & {$[31]$} \\
OnSiteSubstation & {$[50]$} \\
PlannedOutage & {$[21]$} \\
UnplannedOutage & {$[21]$} \\
EmergencyPowerSupplies & {$[19]$} \\
\hline
\end{tabular}




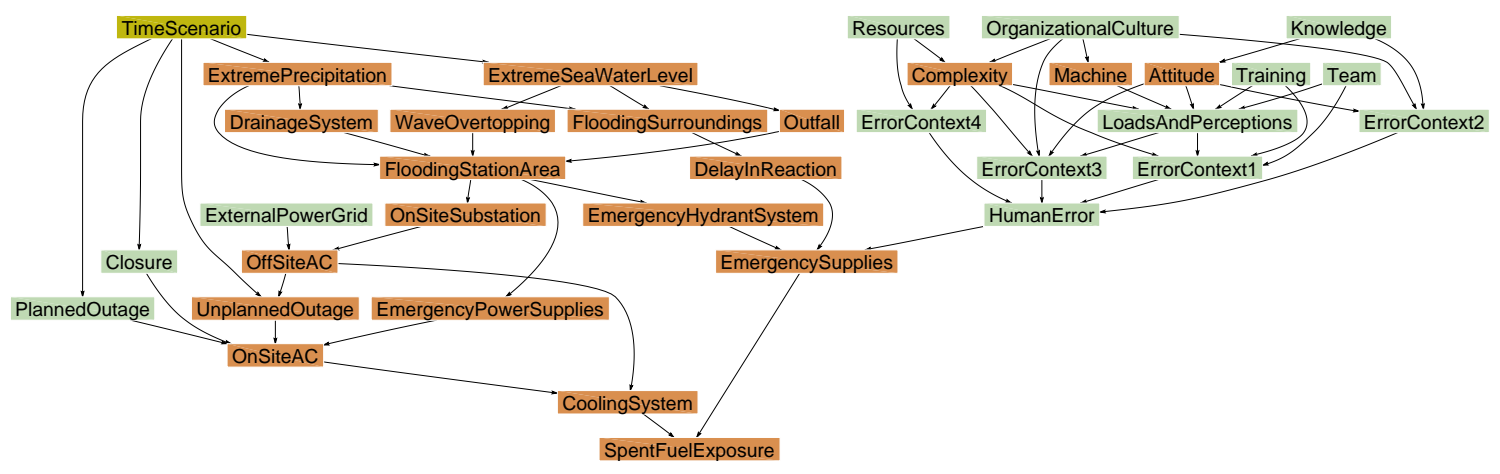

Figure 13: Most probable explanation for the SpentFuelExposure. The orange color refers to the occurrence of the events highlighted

The state of the remaining events involved in the bottom part of the network is considered to be directly inferable from the outcomes of their precursor nodes: SpentFuelExposure is assumed to occur when both the CoolingSystem and the EmergencyPowerSupplies are out of order. Similarly, the failure of the latter happens if the operator does not intervene appropriately (HumanError) or if EmergencyHydrantSystem is not available. Finally, the CoolingSystem failure is caused by station blackouts (i.e., the unavailability of both OffSiteAC and OnSiteAC). Due to lack of information, the presence of reservoirs in the station has been neglected, as well as the topological configuration of the site. This latter assumption is expected to result in a conservative approach.

\subsection{Results}

According to the results, the risk of exposure of the spent fuel grows in time along with the three scenarios considered, as foreseeable on the basis of the natural event intensification. In spite of this, as can be seen in Table 6, the increase is slight, and in none of the time periods does the probability of severe accidents assume significant values. Similarly, the marginal probability of flooding in the station area, as well as the probability of failure of the cooling system, show the same trend. The probability of flooding in the surrounding area is more affected by climate change, as expected, but it also always remains quite low in this case, within an order of magnitude of $10^{-5}$. In addition to

Table 6: Quantification of Risk for Several Events

\begin{tabular}{lccc}
\hline Event & $\begin{array}{c}\text { Scenario1 } \\
(2015)\end{array}$ & $\begin{array}{c}\text { Scenario2 } \\
(2055)\end{array}$ & $\begin{array}{c}\text { Scenario3 } \\
(2099)\end{array}$ \\
\hline On-site Flooding & $1.239 \cdot 10^{-10}$ & $2.483 \cdot 10^{-10}$ & $3.448 \cdot 10^{-10}$ \\
Cooling System & $1.411 \cdot 10^{-10}$ & $2.655 \cdot 10^{-10}$ & $3.620 \cdot 10^{-10}$ \\
Spent Fuel Exposure & $2.592 \cdot 10^{-16}$ & $2.804 \cdot 10^{-15}$ & $2.695 \cdot 10^{-14}$ \\
Flooding in Surroundings & $3.147 \cdot 10^{-07}$ & $1.699 \cdot 10^{-06}$ & $1.176 \cdot 10^{-05}$ \\
\hline
\end{tabular}

quantifying the risks of failure of the different subsystems for different climate scenarios, the model allows one to consider the most probable explanation for the occurrence of SpentFuelExposure, 
introducing the evidence associated with the event. Indeed, as previously highlighted, BNs permit the updating the marginal probabilities of each node on the basis of the evidence available. On the basis of these revised values, it is possible to reconstruct the most likely sequence of events behind the occurrence of the outcome of interest. Fig.13 shows such a path: the events highlighted have the highest occurrence probability conditional to the exposure of the fuel.

\subsubsection{What-if analysis}

Looking at the problem from the opposite perspective, it is possible to estimate the conditional probability of an event of interest as well. Several What if scenarios have been evaluated in order to better understand the distribution of the risk within the model. As is shown in Table 7, in the case of failure of the cooling system or of flooding inside the perimeter of the nuclear island, the risk of exposure grows exponentially in all the analysed cases: these two events are the most significant precursors for the failure of the spent fuel pond system. Other events, such as the flooding in the surrounding area or the malfunctioning of the drainage system, can raise the overall risk of several orders of magnitude. Conversely, the occurrence of human error does not have much impact on the risk of exposure: also, in combination with other events, such as the failure of the drainage system, its contribution is quite low. Nevertheless, it has to be remembered that this part of the modelling is strongly affected by lack of data: the use of expert judgements to better identify the weight of each error contexts could significantly modify the impact of human error on the overall accident scenario. Likewise, introducing evidence regarding the correct functioning of various subsystems,

Table 7: Risk of Spent Fuel Exposure Conditional to Evidence of Correct Functioning of Subsystems

\begin{tabular}{lccc}
\hline Event & $\begin{array}{c}\text { Scenario1 } \\
(2015)\end{array}$ & $\begin{array}{c}\text { Scenario2 } \\
(2055)\end{array}$ & $\begin{array}{c}\text { Scenario3 } \\
(2099)\end{array}$ \\
\hline Cooling System Failed & $1.837 \cdot 10^{-06}$ & $1.056 \cdot 10^{-05}$ & $7.444 \cdot 10^{-05}$ \\
Station Flooded & $2.090 \cdot 10^{-06}$ & $1.129 \cdot 10^{-05}$ & $7.813 \cdot 10^{-05}$ \\
Failure Drainage System & $2.334 \cdot 10^{-12}$ & $2.469 \cdot 10^{-11}$ & $2.333 \cdot 10^{-10}$ \\
Surroundings Flooded & $8.237 \cdot 10^{-10}$ & $1.650 \cdot 10^{-09}$ & $2.291 \cdot 10^{-09}$ \\
Human Error & $2.645 \cdot 10^{-16}$ & $2.832 \cdot 10^{-15}$ & $2.714 \cdot 10^{-14}$ \\
Human Error \& & & & \\
Failure Drainage System & $2.334 \cdot 10^{-12}$ & $2.469 \cdot 10^{-11}$ & $2.333 \cdot 10^{-10}$ \\
\hline
\end{tabular}

it is possible to notice the improved reliability of the overall system, as shown in Table 8. This kind of analysis can become an extremely important support for decision making regarding the eventual adoption of further actions to improve the robustness of the system. For example, in order to evaluate the importance of events affecting the effectiveness of reaction in case of accidents, the probability related to potential causes of this type of failure can be further analysed in order to take the most effective action possible. The results in Table 9 show that, in case of flooding and with regard to the current time scenario, the malfunctioning of the emergency hydrants is the most 
Table 8: Risk of Spent Fuel Exposure Conditional to Evidence on the Correct Functioning of Subsystems

\begin{tabular}{lccc}
\hline What if...? & $\begin{array}{c}\text { Scenario1 } \\
(2015)\end{array}$ & $\begin{array}{c}\text { Scenario2 } \\
(2055)\end{array}$ & $\begin{array}{c}\text { Scenario3 } \\
(2099)\end{array}$ \\
\hline Drainage System Operating & $1.293 \cdot 10^{-19}$ & $6.980 \cdot 10^{-19}$ & $4.832 \cdot 10^{-18}$ \\
Surroundings Not Flooded & 0 & 0 & 0 \\
No Human Errors & $2.592 \cdot 10^{-16}$ & $2.804 \cdot 10^{-15}$ & $2.695 \cdot 10^{-14}$ \\
\hline
\end{tabular}

probable explanation behind the lack of efficient reaction. In light of this, taking action to ensure more auxiliary water supplies would further improve the reliability of the system, decreasing the overall risk of exposure of the spent fuel dramatically.

Table 9: Probable Causes of Failure of Intervention (Emergency Supplies) in Case of Flooding

\begin{tabular}{lc}
\hline What if...? & Scenario1 \\
& $(2015)$ \\
\hline Human Error & $9.148 \cdot 10^{-02}$ \\
Failure Hydrant System & $9.105 \cdot 10^{-01}$ \\
\hline
\end{tabular}

\section{Discussion}

The model proposed identifies three main types of interaction that can contribute to the overall failure of the system: between natural hazards and the facility, between human operators and the technological interface, and finally among the different components of the installation, which constitute a complex internal network of dependencies. Each of these subsets of the overall problem are modelled in view of their internal mechanisms of failure and then represented as the combination of elementary events connected to each other by causal links. This intuitive representation and the flexibility of the approach adopted make the model particularly attractive for future upgrades and improvements, and then potentially useful for more accurate real-world applications in the future.

More generally, as shown by the case study discussed in this paper, BNs proved to be a valid instrument for many aspects of Natech risk analysis: the integration of different models in the general framework has been performed, data from very different sources have been adopted (from projections and experimental records to expert judgement), and the description of the complex system has been carried out considering individual parts and their interactions, finally obtaining a coherent framework that is easy to understand and accessible to non-experts. In addition, the ability to perform inference (including very low probabilities) makes BNs suitable for the analysis of Natech accidents and rare events. Finally, Bayesian updating and the prompt estimation of the risk associated with What if scenarios make this approach extremely attractive for real-time decision support. On the other hand, two main drawbacks of this method have been identified with regard to this kind 
of application. First, the necessity to include natural events as variables of the inference problem implies the need to adopt probabilistic models for their representation, in order to capture their inner randomness and the aleatory uncertainty of data. On the contrary, the restriction to the use of only discrete nodes, typical of traditional $\mathrm{BN}$ and exact inference, can strongly affect data and undermine the credibility of the results. In addition, the assumption of independence between variables not connected by causal links can represent a strong limitation in the application of BNs to natural hazard assessment: different meteorologically driven phenomena often show a more-orless significant degree of correlation that emerges from data but remains hardly explicable through causal relationships, hence are impossible to represent with BNs. Second, a reliable tool for risk assessment cannot avoid the epistemic uncertainty associated with the input. This is all the more true when questionable data such as climate projections or expert judgements are involved. The use of strongly uncertain data can lead to misleading results and, in the case of risk management, to the adoption of ineffective, if not detrimental, actions. In other words, decision makers have to be provided with information about the uncertainty affecting the results on which to base resolutions. BNs lack this capability: also, in this case, it is necessary to overcome the restrictions related to the use of discrete numerical values, adopting models that can capture the epistemic uncertainty of the variables. The use of system reliability methods, as for the sea-wave overtopping model implemented, appears to be a valid solution to include continuous variables and their correlation in the BN framework. In light of this, future research will focus first on the implementation of automatic algorithms to coherently integrate traditional system reliability methods with the BN methodology, and then on extending this technique to more advanced methods that can capture the epistemic uncertainty of data (e.g., adopting convex models and imprecise probabilities).

\section{Conclusions}

Features of BNs such as their inner flexibility and their capability to describe accurately dependencies and causal events related to complex systems and to include data of different natures, make them a promising tool in risk assessment applications. The current study aims to test the potential of BNs in areas of particular significance for Natech events. It focused on the implementation of a $\mathrm{BN}$ for the evaluation of the risk of exposure of spent nuclear fuel stored on site in a power plant subject to flooding hazards. The model proposed addresses the increasing concerns, raised by the public as well as the scientific community, regarding the safety of technological installations and their vulnerability to extreme weather events, as well as the lack of suitable tools for the assessment of the risks related to such hazards. The network includes the effect of climate change on natural hazards to simulate their direct interaction with the facility and that of human error on the resilience and response to internal failures. The application to a real-world case study (namely, the nuclear power plant of Sizewell B) has been analysed, performing inference for three different time scenarios (i.e., 2015, 2055, and 2099). The marginal probabilities of single events, as well as 
those associated with particular accident scenarios, have been computed, revealing a general trend of the risk increasing with time. In spite of this, in none of the analysed accident scenarios did the probability of exposure of the nuclear fuel or of other important precursor events reach significant values. The results of the analysis indicate a good degree of robustness of the facility against current and future external hazards.

Finally, the validity of BNs as a tool for risk assessment of complex systems is attested and their limitations in this field identified. The combination of BNs with structural reliability methods is found to be a suitable solution to overcome some of the BN limitations found in the study. Indeed, it allows including continuous variables in the analysis, improving accuracy without sacrificing the efficiency of exact-inference algorithms.

\section{References}

[1] M. Adorni, H. Esmaili, W. Grant, T. Hollands, Z. Hozer, B. Jackel, M. Munoz, T. Nakajima, F. Rocchi, M. Strucic, N. Tregoures, and P. Vokac. Status report on spent fuel pools under loss-of-coolant accident conditions final report. Technical Report CSNI/R(2015)2, Nuclear Energy Agency, Paris, May 2015.

[2] U.K. Environment Agency. Flooding map, Sizewell area. http://www . environment-agency.gov.uk/(Jul. 11, 2014).

[3] U.K. Environment Agency. Return periods for extreme sea levels, 2013. Rotherham, U.K.

[4] N. Allsop, T. Pullen, J. van der Meer, T. Bruce, H. Schuttrumpf, and A. Kortenhaus. Improvements in wave overtopping analysis: the EurOtop overtopping manual and calculation tool. In Proceedings of the 7th Conference on Coastal and Port Engineering in Developing Countries, Brussels, Belgium, 2008. World Association for Waterborne Transport Infrastructure (PIANC).

[5] P. Baranowsky. Evaluation of station blackout accidents at nuclear power plants. Technical findings related to unresolved safety issue A-44. Draft report for comment. Technical Report NUREG-1032, Nuclear Regulatory Commission, Washington, DC, May 1985.

[6] G.O. Barratt, J.D. Crawley, D.R. Davies, C. Howden, J.N. Kitchener, C. Richardson, A.C. Roberts, and M.J. Sheridan. Sizewell B power station. In S.K. Fullalove, editor, Proceedings of the Institution of Civil Engineers-Civil Engineering, volume 114, pages 36-37, London, 1996. Thomas Telford Services.

[7] Y.Y. Bayraktarli, J. Ulfkjaer, U. Yazgan, and M.H. Faber. On the application of Bayesian probabilistic networks for earthquake risk management. In 9th International Conference On Structural Safety And Reliability, Italy, Rome, Amsterdam, Netherlands, 2005. IOS Press. 
[8] N.L. Bindoff, J. Willebrand, V. Artale, A. Cazenave, J. Gregory, S. Gulev, K. Hanawa, C. Le Quéré, S. Levitus, Y. Nojiri, C.K. Shum, L.D. Talley, and A. Unnikrishnan. Observations: oceanic climate change and sea level. In Climate Change 2007: The Physical Science Basis. Contribution of Working Group I to the Fourth Assessment Report of the Intergovernmental Panel on Climate Change [Solomon, S., D. Qin, M. Manning, Z. Chen, M. Marquis, K.B. Averyt, M. Tignor and H.L. Miller (eds.)], pages 385-432. Cambridge University Press, Cambridge, U.K., 2007.

[9] A. Bobbio, L. Portinale, M. Minichino, and E. Ciancamerla. Improving the analysis of dependable systems by mapping fault trees into Bayesian networks. Reliability Engineering \& System Safety, 71(3):249 - 260, 2001.

[10] S. Caires. Extreme value analysis: wave data. Technical Report 57, Joint WMO/IOC Technical Commission for Oceanography and Marine Meteorology (JCOMM), Geneva, 2011.

[11] S.-P. Cheon, S. Kim, S.-Y. Lee, and C.-B. Lee. Bayesian networks based rare event prediction with sensor data. Knowledge-Based Systems, 22(5):336-343, 2009.

[12] N. Chini, P. Stansby, J. Leake, J. Wolf, J. Roberts-Jones, and J. Lowe. The impact of sea level rise and climate change on inshore wave climate: A case study for East Anglia (U.K.). Coastal Engineering, 57(11):973-984, 2010.

[13] T. Collins and G. Hubbard. Technical study of spent fuel pool accident risk at decommissioning nuclear power plants. Technical Report NUREG-1738, U.S. Nuclear Regulatory Commission Office of Nuclear Regulatory Research Washington, DC, February 2001.

[14] A.M. Cruz, L.J. Steinberg, A. Vetere Arellano, J.-P. Nordvik, and F. Pisano. State of the art in Natech risk management. Technical Report Rep. EUR. 21292, DG Joint Research Centre, European Commission and United Nations International Strategy for Disaster Reduction, Ispra, Italy, 2004.

[15] C. do Nascimento and R. de Mesquita. A human error probability estimate methodology based on fuzzy inference and expert judgment on nuclear plants. In 4th International Nuclear Atlantic Conference-INAC, Rio de Janeiro, Brazil, September 27-October 2009.

[16] M.G. Donat, G.C. Leckebusch, J.G. Pinto, and U. Ulbrich. European storminess and associated circulation weather types: future changes deduced from a multi-model ensemble of GCM simulations. Climate Research, 42(1):27-43, 2010.

[17] M.G. Donat, G.C. Leckebusch, J.G. Pinto, and U. Ulbrich. Examination of wind storms over Central Europe with respect to circulation weather types and NAO phases. International Journal of Climatology, 30(9):1289-1300, 2010. 
[18] A. Duchac and M. Noël. Disturbances in the European Nuclear Power Plant Safety Related Electrical Systems. Journal of Electrical Engineering, 62(3):173-180, 2011.

[19] S.A. Eide, T.E. Wierman, C.D. Gentillon, D.M. Rasmuson, and C.L. Atwood. Industryaverage performance for components and initiating events at U.S. commercial nuclear power plants. Technical Report NUREG/CR-6928, U.S. Nuclear Regulatory Commission Office of Nuclear Regulatory Research, Washington, DC 20555-0001, February 2007.

[20] EDF Energy. EU stress test - Sizewell B. https://www.edfenergy.com/sites/ default/files/jer-srt-stt-pub-fin-007_szb_stress_test_v1.1. pdf (May 16, 2013).

[21] EDF Energy. Sizewell B community reports. http://www.edfenergy.com/ download-centre (Sep. 8, 2014).

[22] OCNS (Office for Civil Nuclear Security). The state of security in the civil nuclear industry and the effectiveness of security regulation. Technical Report OCNS0304, Office for Nuclear Regulation (ONR), Bootle, U.K., April 2003 - March 2004.

[23] CEFAS (Centre for Environment Fisheries and Aquaculture Science). Sizewell waverider post recovery data. http: // cefasmapping.defra.gov.uk/(Aug. 7, 2014).

[24] T. Francis. Extreme Precipitation Analysis at Sizewell: Final Report, 2011. Met Office, Devon, U.K.

[25] K. Groth and A. Mosleh. Development and use of a Bayesian Network to estimate human error probability. In ANS PSA 2011 International Topical Meeting on Probabilistic Safety Assessment and Analysis Wilmington, NC, Wilmington, NC, 2011.

[26] M.S. Hamada, A. Wilson, C.S. Reese, and H. Martz. Bayesian reliability. Springer Science \& Business Media, New York, 2008.

[27] D.P. Hames. Investigation of the Joint Probability of Waves and High Sea Levels along the Cumbrian Coastline. PhD thesis, Faculty of Science and Technology, University of Plymouth, Plymouth, U.K., 2006.

[28] D. Hanea and B. Ale. Risk of human fatality in building fires: A decision tool using Bayesian networks. Fire Safety Journal, 44(5):704-710, 2009.

[29] T.S. Hedges, M.T. Reis, and M. Owen. Random wave overtopping of simple sea walls: A new regression model. In Proceedings of the ICE-Water Maritime and Energy, volume 130(1), pages 1-10, 1998.

[30] N. Houlton. Life Extension of the EDF Energy Nuclear Fleet. In Proceedings of the Nuclear Institute Congress 2013, London, U.K., 2013. Nuclear Institute. 
[31] IAEA (International Atomic Energy Agency). Industry-Average Performance for Components and Initiating Events at U.S. Commercial Nuclear Power Plants. Technical Report IAEA-TECDOC-508, Vienna, Austria, 1989.

[32] D. Kancev and A. Duchac. European Clearinghouse: Events Related to Emergency Diesel Generators. Technical Report JRC83672/EUR 26055 EN, European Commission Joint Research Centre Institute for Energy and Transport, Ispra, Italy, 2013.

[33] D. Kerridge. The threat posed by tsunami to the U.K. Technical report, Department for Environment, Food and Rural Affairs (DEFRA), Flood Management Division, London, U.K., 2005.

[34] N. Khakzad, F. Khan, P. Amyotte, and V. Cozzani. Domino effect analysis using Bayesian networks. Risk Analysis, 33(2):292-306, 2013.

[35] B. Kim and R.R. Bishu. Uncertainty of human error and fuzzy approach to human reliability analysis. International Journal of Uncertainty, Fuzziness and Knowledge-Based Systems, 14(01):111-129, 2006.

[36] J.W. Kim and W. Jung. A taxonomy of performance influencing factors for human reliability analysis of emergency tasks. Journal of Loss Prevention in the Process Industries, 16(6):479 $-495,2003$.

[37] M.C. Kim, P.H. Seong, and E. Hollnagel. A probabilistic approach for determining the control mode in CREAM. Reliability Engineering \& System Safety, 91(2):191-199, 2006.

[38] N. Kopytko and J. Perkins. Climate change, nuclear power, and the adaptation-mitigation dilemma. Energy Policy, 39(1):318-333, 2011.

[39] E. Krausmann and D. Baranzini. Natech risk reduction in the European Union. Journal of Risk Research, 15(8):1027-1047, 2012.

[40] J. Leake, J. Wolf, J. Lowe, P. Stansby, G. Jacoub, R. Nicholls, M. Mokrech, S. NicholsonCole, M. Walkden, A. Watkinson, et al. Predicted wave climate for the U.K.: towards an integrated model of coastal impacts of climate change. In ASCE, editor, Proceedings of the Tenth International Conference on Estuarine and Coastal Modeling Congress, pages 393406, New York, 2007.

[41] B. Liscouski and W. Elliot. Final report on the August 14, 2003 blackout in the United States and Canada: Causes and recommendations, 2004. U.S.-Canada Power System Outage Task Force. A report to U.S. Department of Energy, Washington, DC.

[42] Magnox. Sizewell A: Response to EU stress tests following the events at Fukushima, Japan, 2011. Barkeley, CA. 
[43] G.I. Maldonado. The performance of North American nuclear power plants during the electric power blackout of August 14, 2003. In Nuclear Science Symposium Conference Record, 2004 IEEE, volume 7, pages 4603-4606, New York, 2004. IEEE.

[44] D. Maraun, T. Osborn, and N. Gillett. United Kingdom daily precipitation intensity: improved early data, error estimates and an update from 2000 to 2006. International Journal of Climatology, 28(6):833-842, 2008.

[45] MathWorks. MATLAB [computer software]. Natick, MA.

[46] MetOffice. U.K. Climate Projections: Projections of sea level rise and storm surge trends for U.K. waters. http://ukclimateprojections-ui.metoffice.gov.uk/(Jul. 7, 2014), Department for Environment, Food and Rural Affairs (DEFRA), London, U.K.

[47] MetOffice. U.K. Climate Projections: key findings summary spreadsheet, 2014. Department for Environment, Food and Rural Affairs (DEFRA), London, U.K.

[48] K. Murphy. The Bayes net toolbox for MATLAB. Computing Science and Statistics, 33(2):1024-1034, 2001.

[49] K. Murphy. Software for graphical models: A review. International Society for Bayesian Analysis Bulletin, 14(4):13-15, 2007.

[50] D. Nack. Reliability of substation configurations, 2005. Iowa State University, Ames, IA.

[51] N. Nakicenovic and R. Swart. Special report on emissions scenarios, volume 1 of Intergovernmental Panel on Climate Change. Cambridge University Press, Cambridge, U.K., 2000.

[52] R.J. Nicholls, P.P. Wong, V.R. Burkett, J.O. Codignotto, J.E. Hay, R.F. McLean, S. Ragoonaden, and C.D. Woodroffe. Coastal systems and low-lying areas. In In: Climate Change 2007: Impacts, Adaptation and Vulnerability. Contribution of Working Group II to the Fourth Assessment Report of the Intergovernmental Panel on Climate Change [M.L. Parry, O.F. Canziani, J.P. Palutikof, P.J. van der Linden and C.E. Hanson, (Eds.)]., pages 315-356. Cambridge University Press, Cambridge, U.K., 2007.

[53] E. Patelli, H.M. Panayirci, M. Broggi, B. Goller, P. Beaurepaire, H.J. Pradlwarter, and G. I. Schuëller. General purpose software for efficient uncertainty management of large finite element models. Finite Elements in Analysis and Design, 51:31-48, 2012.

[54] J. Pearl. Bayesian networks: A model of self-activated memory for evidential reasoning. In Proceedings of the 7th Conference of the Cognitive Science Society, pages 329-334, University of California, Irvine, CA, 1985.

[55] J. Pearl and S. Russell. Bayesian networks. Technical Report R-277, UCLA Cognitive Systems Laboratory, November 2000. MIT Press, Cambridge, MA, 157-160. 
[56] J.G. Pinto, E. Fröhlich, G. Leckebusch, and U. Ulbrich. Changing European storm loss potentials under modified climate conditions according to ensemble simulations of the ECHAM5/MPI-OM1 GCM. Natural Hazards and Earth System Science, 7(1):165-175, 2007.

[57] M. Rauthe, M. Kunz, and C. Kottmeier. Changes in wind gust extremes over Central Europe derived from a small ensemble of high resolution regional climate models. Meteorologische Zeitschrift, 19(3):299-312, 2010.

[58] M.T. Reis, K. Hu, T.S. Hedges, and H. Mase. A comparison of empirical, semiempirical, and numerical wave overtopping models. Journal of Coastal Research, 24(sp2):250-262, 2008.

[59] S.S. Rivera, P.A. Baziuk, and J. NúñezMcLeod. Fuzzy uncertainties in human reliability analysis. In Proceedings of the World Congress on Engineering, WCE 2011, volume 2, pages 970-975, London, U.K, July 6-8 2011.

[60] S.J. Russell and P. Norvig. Artificial Intelligence: A Modern Approach, volume 25. PrenticeHall, Egnlewood Cliffs, 1994.

[61] S.I. Seneviratne, N. Nicholls, D. Easterling, C.M. Goodess, S. Kanae, J. Kossin, Y. Luo, J. Marengo, K. McInnes, M. Rahimi, M. Reichstein, A. Sorteberg, C. Vera, and X. Zhang. Changes in climate extremes and their impacts on the natural physical environment. In In: Managing the Risks of Extreme Events and Disasters to Advance Climate Change Adaptation [Field, C.B., V. Barros, T.F. Stocker, D. Qin, D.J. Dokken, K.L. Ebi, M.D. Mastrandrea, K.J. Mach, G.-K. Plattner, S.K. Allen, M. Tignor, and P.M. Midgley (eds.)]. A Special Report of Working Groups I and II of the Intergovernmental Panel on Climate Change (IPCC)., pages 109-230. Cambridge University Press, Cambridge, U.K., 2012.

[62] R.M. Sorensen. Basic coastal engineering. Springer, New York, 3 edition, 2006.

[63] L.J. Steinberg, H. Sengul, and A.M. Cruz. Natech risk and management: an assessment of the state of the art. Natural Hazards, 46(2):143-152, 2008.

[64] D. Straub. Natural hazards risk assessment using Bayesian networks. In Proceedings of the 9th Conference on Structural Safety and Reliability (ICOSSAR05), pages 2535-2542, Rome, 2005.

[65] D. Straub and D. Kiureghian. Bayesian network enhanced with structural reliability methods: methodology. Journal of engineering mechanics, 136(10):1248-1258, 2010.

[66] C. Svensson and D.A. Jones. Dependence between extreme sea surge, river flow and precipitation in Eastern Britain. International Journal of Climatology, 22(10):1149-1168, 2002. 
[67] S. Tolo, E. Patelli, and M. Beer. Bayesian network approach for risk assessment of a spent nuclear fuel pond. In Proceedings of the Second International Conference on Vulnerability and Risk Analysis and Management (ICVRAM) and the Sixth International Symposium on Uncertainty, Modeling, and Analysis (ISUMA), pages 598-607, Reston, VA, 2014. ASCE.

[68] K.E. Trenberth, P.D. Jones, P. Ambenje, R. Bojariu, D. Easterling, A. Klein Tank, D. Parker, F. Rahimzadeh, J.A. Renwick, M. Rusticucci, B. Soden, and P. Zhai. Observations: Surface and atmospheric climate change. In Climate Change 2007: The Physical Science Basis. Contribution of Working Group I to the Fourth Assessment Report of the Intergovernmental Panel on Climate Change [Solomon, S., D. Qin, M. Manning, Z. Chen, M. Marquis, K.B. Averyt, M. Tignor and H.L. Miller (eds.)]., pages 235-336. Cambridge University Press, Cambridge, U.K., 2007.

[69] A.W.H. Turnpenny, J. Coughlan, B. Ng, P. Crews, R.N. Bamber, and P. Rowles. Cooling water options for the new generation of nuclear power stations in the U.K. Technical Report SC070015/SR3, Environment Agency, Bristol, U.K., 2010.

[70] P. Weber, G. Medina-Oliva, C. Simon, and B. Iung. Overview on Bayesian networks applications for dependability, risk analysis and maintenance areas. Engineering Applications of Artificial Intelligence, 25(4):671-682, 2012.

[71] M. Weightman, P. Jamet, J.E. Lyons, S. Samaddar, G. Chai, S.K. Chande, A. Godoy, A. Goryachev, A. Guerpinar, J.C. Lentijo, I. Lux, and D.E. Sumargo. IAEA international fact finding expert mission of the nuclear accident following the Great East Japan earthquake and tsunami. Fukushima Dai-ichi NPP, Japan, 2011. Mission Report.

[72] J. Wolf. Coastal flooding: impacts of coupled wave-surge-tide models. Natural Hazards, 49(2):241-260, 2009.

[73] F. Zheng, S. Westra, and S.A Sisson. Quantifying the dependence between extreme rainfall and storm surge in the coastal zone. Journal of Hydrology, 505:172-187, 2013. 
